\title{
Strengthening the Relational Trust between a Professional Leader
} and the Team

By Brigitte Alamani

\author{
A Thesis \\ Submitted to the Victoria University of Wellington in fulfillment of the requirements \\ of the degree of Master of Education \\ Victoria University of Wellington 2017
}




\section{Abstract}

Relational trust is defined by Bryk and Schneider as the "connective tissue that binds individuals together to advance the education and welfare of students" (2003, p.44). It is the Professional Leader's role to consciously look for ways to cultivate closeness within the team, as it is this trusting relationship with each other that provides the impetus for teachers to strive for optimal performance individually and collectively (Bloom, 2003). The aim of this research was to discover what leadership conceptual understandings and practices would help strengthen the relational trust between a Professional Leader and the team. This research took form of a case study within an interpretive paradigm. Data were collected from four different sources - two online surveys, professional conversations, four observations and anecdotes from a personal journal. Findings revealed five key attributes that were important for a Professional Leader to have in order to strengthen their relational trust with the team. These are: communication, active listening, availability/approachability, accountability and consistency. Several recommendations for three stakeholders arise from this study - for centre owners/managers, for the Ministry of Education and the Education Council, and finally, for researchers. 


\section{Acknowledgements}

Undertaking this research has not been an easy task! Challenges were met along the way, and if it were not for the following people, finishing this thesis would not have been possible:

First of all, I want to acknowledge my husband Jayson, and daughter Chloe, who have both been incredibly understanding of my 'constant absence' especially in the last few months as I frantically finish writing this thesis. Thank you, Jayson, for being so supportive and encouraging this whole time. Thank you for believing in me. I love you, and Chloe more than words can say.

Next, I want to thank my colleagues, for trusting me with your honest thoughts and opinions throughout the data collection process. Thank you, too, for being so supportive throughout this process, and for cheering me on, especially on days when everything felt a bit overwhelming. I am honoured to be working alongside you all.

Finally, my heart felt thanks to my mentors, Dr. Anne Meade, and Dr. Kate Thornton. Thank you for generously sharing your expert knowledge on leadership in early childhood education. Thank you Anne, for always believing in my leadership capabilities. Thank you Kate, for gently pushing me to make my thesis better than it was. I appreciate you both very much.

Thank you all.

Brigitte Alamani 


\section{Table of Contents}

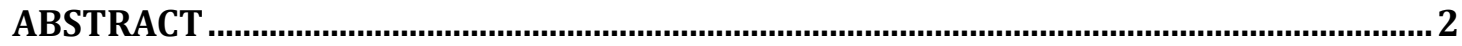

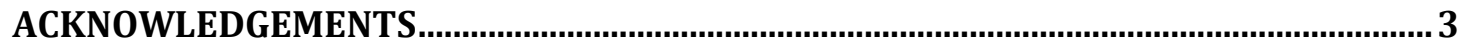

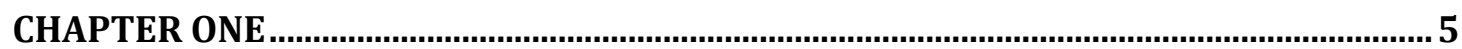

INTRODUCTION

CHAPTER TWO

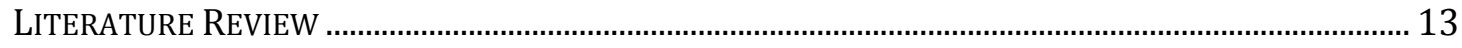

CHAPTER THREE

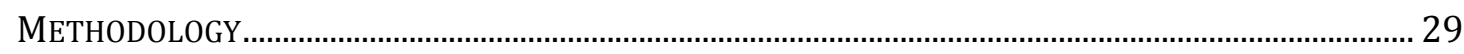

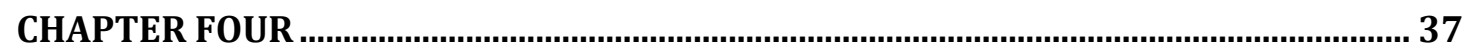

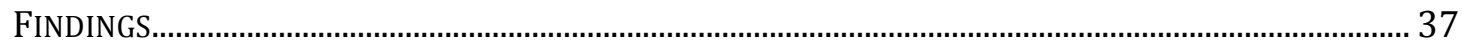

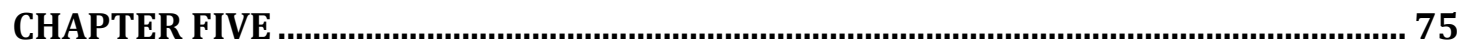

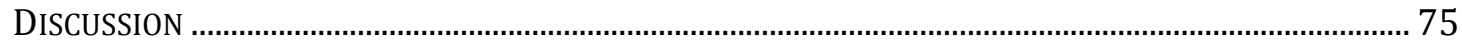

CHAPTER SIX

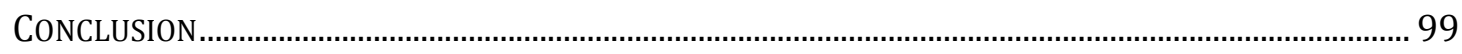

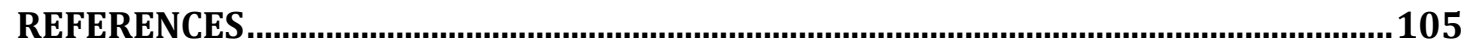

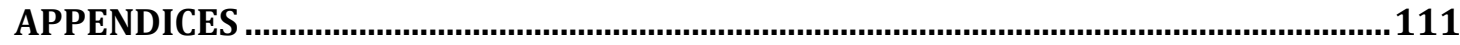

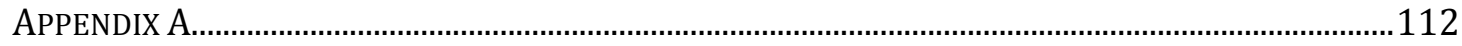

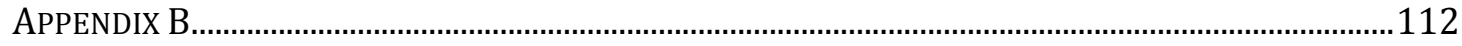

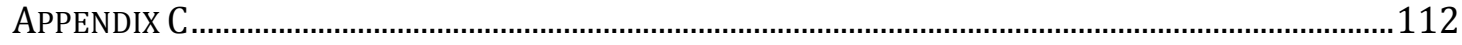

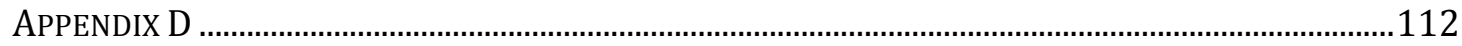

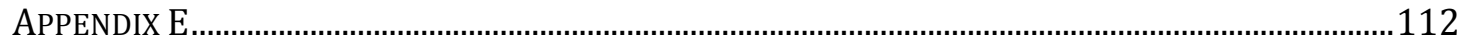

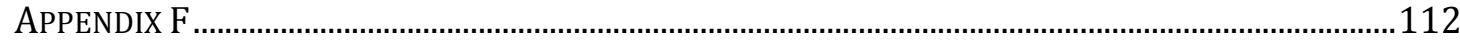




\section{Chapter One}

\section{Introduction}

Based on extensive research focused on leadership practices, James Kouzes and Barry Posner discuss in their book, The Leadership Challenge (2012), the significance of building relationships with and among the people you are leading. When you have a meaningful relationship with another person you work with, you work more effectively together. Common goals are shared and unified effort is carried out towards the achievement of the common goals. Effective leaders purposefully work towards building these relationships and spend time focusing their efforts in ways that will build connections with the people they lead (Kouzes \& Posner, 2012). Ross Notman shared similar findings from his case studies of New Zealand schools and an early childhood centre, and concluded "successful educational leaders develop relationships as a priority" (p.142). More over, if these relationships are characterized by certain attributes like honesty and reliability, trust in the Professional Leader develops (Thornton, 2010), which is what this research will focus on.

This chapter briefly presents the current context of leadership in early childhood education. It then discusses the significance of relationships between a Professional Leader and the team, which leads to this study's particular focus on strengthening relational trust. Finally, it provides a brief overview of the following chapters. 


\section{Current Context of Leadership in Early Childhood Education}

Leadership is identified as an important factor in the provision of a quality early childhood education service (Bloom \& Bella, 2005; Education Review Office, 2011; Grey, 2004; Rodd, 2013). However, there is a noticeable paucity of New Zealand literature that explicitly explains what leadership means for the early childhood sector. A literature review showed that there has been minimal progress with raising the profile of leadership within ECE in New Zealand since Thornton et al. published the report Conceptualising Leadership in Early Childhood Education in Aotearoa New Zealand in 2009. Consequently, many of the issues and dilemmas identified in this report I believe still stand true to this day.

At present time, there are no existing literatures stating any requirement for any early childhood education (ECE) teacher to undergo any leadership training before taking on any leadership roles, which means there are currently many teachers who are in leadership positions in early childhood setting who have limited, or lack of professional leadership knowledge and training (Aitken, 2013). Leadership is a complex responsibility (Fasoli et al, 2007). If teachers are coming into leadership roles without any prior leadership knowledge or training, how can they be successful in their role?

\section{Relationships}

Notman (2011) concluded in his research that an investment in and valuing of relationships is key to successful leadership. Similarly, Kouzes and Posner (2007) found a message was noticeably clear throughout their research and that is 
"leadership is a relationship between those who aspire to lead and those who choose to follow" (p.24). They went on to explain that the quality of this relationship is of huge significance and influence to the accomplishment of goals and realization of a collective vision. Therefore,

"Success in leadership...have been, are now, and will continue to be a
function of how well people work and play together...will be wholly
dependent upon the capacity to build and sustain those human
relationships..." (Kouzes \& Posner, 2007, p.25).

Though Kouzes and Posner's work (2012) was not education based, it's focus on relationships rings true for early childhood education. Relationships lie at the heart of early childhood education pedagogy, curriculum and practice. As Emmi Pikler, a Hungarian pediatrician and well-respected infant and toddler specialist stated: "The relationship is all. It is a matter of life to the baby" (Brownlee, 2008, p.29). The significance of relationships is clearly evident in the New Zealand early childhood curriculum, Te Whāriki (Ministry of Education, 1996) as it is one of four key principles. The curriculum emphasizes that children learn through relationships and interactions. According to early childhood theories, Urie Bronfenbrenner, a child's development is influenced by all the different levels of "Ecological Systems" they are a part of and by the way those systems interact with each other (Bronfenbrenner, 1994). Along with the child's family, early childhood settings are part of what Bronfenbrenner termed as microsystem - the most influential level of the ecological system theory as it is the system that is closest and have direct contact with the child. Children learn about different aspects of a relationship from watching the 
adults around them interact with each other - how to communicate, problem solve, care about each other and work together. Therefore, the quality of interactions between these immediate adults in a child's life must be excellent.

To support teachers in cultivating these quality connections, there are numerous literatures available that discuss the importance of and how to develop a trusting relationship with the child's family (such as Te Whāriki, along with other educational pedagogies like Reggio Emilia philosophy, and Resources for Infants Educarers ${ }^{\circledR}$ - RIE) to promote positive learning outcomes for the child's holistic development. There are also many literatures about the importance of team building and establishing professional learning communities - PLC (for example, Hipp \& Huffman, 2010; Thornton \& Cherrington, 2014) to nurture a culture of kotahitanga (unity) amongst the team. However, most PLC studies are pertinent within a school context, and not so much within the early childhood sector.

\section{Teachers come first: A personal opinion}

Many leaders have advised me in the past that children should always come first in our profession. Early childhood education after all is about children. Many have also advised that ensuring families are 'happy' (how ever one would define happiness) must be a priority for any Professional Leader. I agree with the sentiments of both, however, must I choose who should come first, I disagree that it should either be the families, or even the children. I have always believed that as a Professional Leader, my priority should be the group of teachers I am responsible for leading. My priority 
should be establishing a trusting relationship and strengthening the relational trust with the team first and foremost.

Toni Christie, author of Leading with Heart and Soul (2016) and Director of the Childspace Early Childhood Institute in Wellington, New Zealand, stated that centre leaders must always put their teachers first. She explained it -

"A good leader can create an environment where teachers are enjoying themselves, synergy is created and there is a felling of respect, equality, tolerance, passion and enthusiasm. This does not happen when a manager puts the children first, it happens when they put their teachers first. They, in turn, put the children first, and in my experience whenever children are happy, the parents will always be happy" (Christie, 2016, p.35).

When leaders look after teachers' well-being first and ensure their needs are met, teachers' emotional 'fuel tank' gets refueled. Teachers will feel they are heard and valued. They will feel re-energized, and their passion and commitment rekindled to provide the best possible outcomes for children. They learn to trust the leader as someone who has teachers' best interest in mind. Children will in turn feel and be holistically nurtured and cared for - their emotional needs are met - by emotionally healthy teachers who are in their microsystem. Children grow to be confident and secure within these important relationships. As a result, parents see their child to be settled and happy within the early childhood setting. The parents, too, become happy and satisfied with the setting's educational programme and service, and 
successively provide this feedback to the centre's professional leader. It is a logically simple 'circle of life'.

\section{Building Relational Trust}

Though there are many literatures discussing the importance of fostering relationships and developing trust within the team (for example, Notman, 2011; Carter \& Curtis, 2010), there is a lack of literature that specifically discusses how to build trusting relationships between a Professional Leader and the team. What do leaders, especially 'new' leaders, need to know and do to be able to successfully lead a team? More over, there is a noticeable gap in research that specifically discusses leadership strategies a professional leader can use to cultivate a positive working relationship and develop relational trust with the team.

This prompted the development of the following research question:

What leadership conceptual understandings and practices will help strengthen the relational trust between a Professional Leader, and the team?

Through this study I aimed to identify practices that would help strengthen the relationship, in particular, the relational trust between Professional Leader and the team. Findings gained through this study will be used to 'bridge the gap' and add to the current literature on effective leadership in early childhood education. 


\section{Researcher Background}

I have been an early childhood teacher for nearly fifteen years. For more than half of my teaching career, I have also been in leadership positions, although most of these roles were mainly that of a leader's support, i.e. Assistant Supervisor. In 2015, for the first time, I took on the "Professional Leader" role of a Head Teacher and the responsibility of leading a team of nine teachers at an early childhood centre in Wellington, New Zealand.

I had been working in said centre for at least three years as an Education Leader support for the Head Teacher with the responsibility of helping guide the teaching team in 'living' the centre's philosophy, and ensuring that curriculum planning and implementation, assessment and evaluation are continually improving. The promotion into the Head Teacher role meant my responsibility now extended beyond just educational leadership. Being the overall person responsible for the daily running of the centre, it was now my role to contribute to strategic planning; manage relationships and promote professional learning amongst the team through mentoring and coaching; manage relationships with families; and manage organizational systems. I have always felts confident with the administration and management aspect of a leadership position, however, I felt uncertain about how my promotion would affect my relationship with the team. I expected our relationship would change now that I was in a more senior role. This was what prompted me to undertake this study - to discover and learn leadership conceptual understandings and practices that would support me through this role change, and help sustain my 
existing relationship with the team, as well as strengthen the relational trust between the team and I.

\section{Organisation of the Thesis}

Chapter two reviews current literature relating to leadership within early childhood education. It specifically reviews existing literature relating to the development of relational trust. Chapter three discusses the research methodology used in this study. Chapter four presents findings gathered from data, which formed the basis of this study. Chapter five provides an in depth discussion of the thematically analyzed data and chapter six highlights my conclusion and recommendations for where to next with this topic. 


\section{Chapter Two}

\section{Literature Review}

This literature review firstly looks at the definition of leadership, with a brief focus on the notion of distributed leadership. It then examines how the concept of leadership is currently viewed within an early childhood education context. Next, it discusses the role of vision leadership, along with a summary of features that makes up a professional learning community. Finally, it discusses the term 'relational trust' and the four criteria for its discernment within an educational setting.

\section{What is leadership?}

A review of literature revealed that there are many definitions of leadership within early childhood education and that it can be practised in different ways and takes many forms (Aitken, 2013; Bloom, 2003; Rodd, 2013; Siraj-Blatchford \& Hallet, 2014). At its simplest definition, leadership is often described as a people-oriented process where two or more people are influenced to come together and achieve a common goal (Rodd, 2013). It is also described as the process in which "one person sets the purpose or direction for one or more other persons and gets them to move along together with him or her and with each other in that direction with competence and full commitment" (Briggs \& Briggs, 2009, p.29). Leadership traditionally resides in this 'one person' who chooses to accept and embrace the roles and responsibilities that comes with it. However, in recent years, there has been a strong shift from viewing leadership as being a one-person job, to being more shared and distributed (Aitken, 2013; Clarkin-Phillips, 2009). 


\section{Distributed Leadership}

Adopting a distributed leadership perspective shifts the focus from leaders to leadership (Harris, 2009; Rodd, 2013; Spillane, 2006). Alhough the traditional leadership roles and positions (of supervisors and/or managers for example) are still relevant, leadership practice within this distributed model is of upmost importance. How leadership is defined within any setting frames how people will participate in it (Lambert, 1998). This reciprocal relationship is characterized by the way followers interpret the situation and respond to the leader, which in turn influences how leaders think and act. A distributed leadership model "de-centres the leader" (Harris, 2003).

In contrast to the traditional, hierarchical system of leadership, it is this collaborative interaction between each member of the group that defines distributed leadership. It is believed that, by working together, expertise is developed (Harris, 2009). Lambert (cited in Jovanic \& Roder, 2008) termed this interactive process as 'capacity building' wherein encouraging leadership capacity comes from the "joint meaning making activity that is bound up with the construction of shared visions and the refining of new practices" (p.71). Involving many people in leadership activity is the basis of distributed leadership in action (Harris, 2009). In order to do this, one must have a good understanding of how a group of people come together and become an effective team. Psychologist Bruce Tuckman provided helpful insight to how a team develops over time through his work "Stages of Team Development" (Tuckman \& Jensen, 1977) 


\section{Stages of Team Development}

Bruce Tuckman provided a model that explains how a team develops through four key stages (Tuckman \& Jensen, 1977). The first stage is 'forming', which is the stage when a group comes together for the first time, and its focus is primarily on building relationships within the team and creating the group's vision and goals. In the 'forming' stage team members demonstrate uncertainty and anxiety, as each person would be cautious with their behaviour, which is often driven by the want to be accepted by all. It is during this stage when roles and expectations of each person must be clarified to avoid any future misunderstanding.

The next stage is 'storming'. In this stage team members feel more comfortable expressing opinions, therefore conflict may emerge as different perspectives and ideas clash with each other, which could cause frustration and the team may lose motivation. This stage can also become destructive if the group's leader allows conflict to get out of hand. However, if managed well, getting through this stage of conflict and disagreements can make a team stronger, more versatile and able to work better collectively. This 'storming' stage is necessary for the growth of the team, which can take up to three or four meetings before transitioning into the 'norming' phase (Tuckman \& Jensen, 1977).

Once a group manages to work through the conflict, it can move on to the third stage of team development, known as the 'norming' stage. This is when team members becoming increasingly positive about the team as a whole, about each other as individuals and what the team is doing collectively. Morale is high as every team 
member actively acknowledges each other's experiences and abilities. The team respect and trust each other. Roles and responsibilities are clear and established, allowing individuals to proudly showcase their strengths and skills. In this stage leader can step back and allow others to take greater responsibility. If a team reaches the 'norming stage' they are probably close to succeeding and achieving their goal (Tuckman \& Jensen, 1977).

Finally, the fourth stage is the 'performing' stage. This is when there is a high level of trust and respect within the team, where team members have come to accept each other, individuals are competent and autonomous, and able to handle the decision making process without the need for a leader's supervision. Leadership within the team is flexible and distributed, with each member of the team able to work independently with no interference or participation needed from the leader. The team has a shared vision, is more strategically aware and knows clearly the purpose of and why they are doing what they're doing. Everyone demonstrates a great working relationship and support for each, therefore can effectively function as a unit at a high level and able to find effective strategies and work through any conflict or issues (Tuckman \& Jensen, 1977).

\section{Leadership in Early Childhood Education}

Although there is still a place for formal leadership roles in a model of distributed leadership, the job of those in formal leadership positions is to hold the pieces of the organization together in a productive relationship by creating a common culture of expectations (Harris, 2009). The ideology within this leadership framework shifts the 
responsibility of 'doing' and 'thinking' from just one person, the positional leader, to many, the team members, incorporates and allows for many individual viewpoints, thus making the best use of everyone's unique strengths and capabilities. For this reason, a distributed leadership model is often used for explaining leadership in early childhood education (ECE). However, agreeing to one, unified description of what leadership means in ECE has proved challenging.

Though there has been a gradual increase in literature over the years that focuses on leadership specifically in ECE, for example Aitken, 2013; Bloom, 2003; Fasoli, Scrivens \& Woodrow, 2007; Jordan, 2008; Ord et al., 2013; Rodd, 2013; Siraj-Blatchford \& Hallet, 2014; Thornton et al., 2009, a paucity of shared understanding as to what leadership in ECE actually means or looks like still exists, possibly due to the diversity of the sector, with its diverse structures and programmes (Ord et al, 2013).

A review of the literature identified reluctance by ECE teachers to identify with leadership roles or see themselves as leaders (Aitken 2013; Aubrey, 2007; Ord et al, 2013; Thornton et al., 2009) as a possible reason for this lack of collective understanding. Rodd (2013, p.5) argues that leadership "appears to be a phenomenon that remains enigmatic for many in early childhood", that is, it means different things to different people in different contexts. How leadership is practised varies between different situational or cultural contexts. Even the term used to describe those in leadership positions vary between ECE settings. While the Education Council of Aotearoa New Zealand (EDUCANZ), a professional organization for teachers across the sector that is also an independent statutory body, uses the 
term 'Professional Leader' to encompass school principals and ECE leaders, ECE leaders across the sector tend to have titles such as manager, director, supervisor, senior teacher, head teacher or team leader (Thornton et al., 2009). Nonetheless, reference to names and titles is not always helpful as responsibilities and practices that go with each name or title can vary from context to context. This in turn does not help to shed light on or improve understanding of leadership practices, complexities and potential in the ECE sector.

\section{Lack of Leadership Development Programmes in ECE}

A key cause for the paucity of shared understanding about leadership is the lack of leadership development programmes within and specific to the ECE sector. In 2009, Thornton et al. published an occasional paper where it highlighted the noticeable gap in research and literature when it comes to defining and acknowledging the importance of leadership within ECE. In contrast, there is an extensive recognition of the significance of leadership development within the school sector. Examples of this are the recently held conference 'National Leadership Forum: Communities of Learning' in November 2016, and the variety of leadership resources posted on the EDUCANZ website (https://educationcouncil.org.nz/content/leadership-resources), which are all aimed for school leaders.

There has been an increase in specific leadership training in ECE, though visibly slow in progress compared to the school sector, since Thornton et al (2009) published their report. For example, in 2013, Te Tari Puna O Aotearoa published a research paper about 'Developing Pedagogical Leadership in Early Childhood Education' (Ord 
et al, 2013). In 2014, the Ministry of Education released the resource Leadership in early childhood education for '5 out of 5 ' children to "stimulate leadership conversations and actions (that would) ensure 5 out of 5 children benefit fully from early childhood education". Some tertiary institutions have also developed qualifications that are specific to leadership for the ECE sector. For example, ECE teaching provider Te Rito Maioha Early Childhood New Zealand (formerly Te Tari Puna O Aotearoa) now offers a Postgraduate Diploma in Leadership (ECE). This qualification is about "theorizing and applying leadership practice in early childhood education contexts". There are no current literatures stating any requirement that an ECE teacher must undergo any leadership training before taking on any leadership roles. This means that aspiring ECE leaders are coming into the role completely unprepared for and oblivious to the complexities that leadership brings. As Rodd (2013) explained,

Teaching qualifications and experience, while valuable, do not offer adequate preparation for the formal, complex leadership and administrative roles and responsibilities required for leading contemporary inclusive, integrated, multi-disciplinary, multi-agency early childhood services (p.39).

\section{The Difference between Leadership and Management}

There is also a widespread confusion between the notions of leadership in ECE with the concept of management (Thornton et al, 2009), which contributes to the lack of collective understanding of what leadership in ECE means. Because both terms are being used interchangeably and are inherently linked and interwoven, it has proved difficult to explicitly define and differentiate one over the other. However, it is 
important to note that effective leadership in ECE is more than management (Aubrey, 2007).

Management deals with the day-to-day work (Siraj-Blatchford \& Hallet, 2014). Managers plan, coordinate, control and supervise. Management is more focused on maintenance tasks - to keep up, perpetuate and sustain procedures that would ensure the smooth daily running of the organization. Management tasks can be enacted without the need to be in a leadership position. Leaders, on the other hand, focus on the future. Leaders see managerial tasks as opportunities to empower and engage members of their team. Leaders build and communicate with the team a shared vision, inspire commitment to and motivate collaboration towards achieving shared goals, as well as model and distribute responsibilities to every member of the team (Siraj-Blatchford \& Hallet, 2014).

While managers focus on the narrow and specific details of getting through the day, leaders are oriented towards the future, and radiate a vision that is "grounded in philosophy, values and beliefs, which in turn guides policy, day-to-day operation, procedures and innovation. It is manifested through strategic planning that grows out of reflection" (Rodd, 2013, p.20).

\section{The Role of Vision in Leadership}

While the ability to implement policies and procedures, orchestrate tasks, budget resources and organize staffing are important management skills to have, a leader's main role should be to formulate and articulate a vision in a way that will inspire and 
motivate others to work collaboratively towards attaining that vision (Hipp \& Huffman, 2010).

A vision is commonly referred to as the 'big picture', the why we do the things we do. Rodd (2013) called a vision "the communicated direction" (p.127) while Bloom (2010) likened it with a "lighthouse, a point in the distance that gives direction through the fog" (p.27). A vision guides ECE services' decision making that will support towards the achievement of their preferred future - their aspirations, what they want to be.

Rodd (2006) described the role of vision in leadership as...

“...the means by which leaders captivate the imagination of their followers and engage loyalty and support. It is the philosophy that is spelt out by the leader and adopted by early childhood practitioners which provides the direction for and gives meaning to innovative decisions... Vision provides direction for and sustain action in the team, can boost morale and selfesteem, and acts as a buffer against stress during periods of change" (p.26)

A vision, however, cannot be just one person's idea. It is the leader's central task to involve others in creating a shared vision. A shared vision must reflect or support each team member's values, beliefs and ideas for it to captivate and motivate everyone to work together towards its realization, for the organization to develop a professional learning community (Hipp \& Huffman, 2010). 


\section{Professional Learning Communities}

A professional learning community (PLC) is described as a group of "professional educators working collectively and purposefully to create and sustain a culture of learning for all students and adults" (Hipp \& Huffman, 2010, p.12). A professional learning community, therefore, is one where teachers participate in decision making, have a shared vision and a sense of purpose, engage in collaborative work and accept joint responsibility for the outcomes of their work.

Stoll (2011) listed other characteristics that define a professional learning community, and this includes:

- Reflective professional enquiry: This includes a reflective dialogue and frequent examination of teachers' practice through observation and analysis.

- Collaborative enquiry: Achievement of a shared vision is linked to collaborative activities between members of a PLC.

- Promotion of group and individual learning: Teachers are also learners, where their "professional self renewal is communal rather than solitary" (Stoll, 2011, p.106).

- Trusting relationships: Effective PLCs develop positive relationships and collegiality that are characterized by 'relational trust', a term used by Bryk \& Schneider (2002). 
For the purpose of this study, the literature review will now focus on the notion of 'relational trust' within relationships.

\section{Trust}

Within professional learning communities, Bloom (2003), Curtis \& Carter (2010), Notman (2011) \& Rodd (2013) have all specifically discussed the significance of having trust amongst the team. But what is trust, and what does it mean within an ECE context?

Trust is defined as the willingness to be vulnerable to another person and is seen as a vital element in well functioning organisations (Stephenson, 2009). Empirical results based on Tschannen-Moran and Hoy's research (1998) show that trust is considerably influenced by the social context in which it is embedded and is associated with a sense of authenticity, collegiality, professionalism and openness. According to Robinson, Hohepa and Lloyd (2009), "trust is critical where the success of one person's efforts is dependent on the contribution of others" (p.183). Without trust, team members will be less open about their mistakes and weakness, resulting to lack of engagement in the robust debate of ideas (Thornton, 2010).

\section{Three Levels of Trust}

Lewicki and Bunker (1996) wrote about three basic levels of trust - deterrence based trust, knowledge based trust, and identity based trust. These different levels of trust develop as the relationship grows over a period of time. Deterrence based trust is the most fundamental level of trust in all relationships. This type of trust is mostly 
governed by rules, such as policies and procedures within an organization, that prevent one person from taking advantage of, or harming another person. This usually occurs when people meet for the first time and begin to work together (Lewicki and Bunker, 1996).

Repeated interactions over time lead to the growth into the next phase, which is the second level of trust called knowledge based trust. This level of trust is based on one's growing experience with and increasing knowledge and predictability of another person's behavior. With this understanding one will have a fair idea of how the other will behave in a given situation. This develops as a relationship matures further, the possibility for a deeper connection with each other emerges (Lewicki and Bunker, 1996).

The third, and most intimate, level of trust is identity-based trust. This kind of trust is characterized by feelings of personal attachment and identification of the other person's intentions and desires, their vision and goals. Identity-based trust exists when there is complete empathy and begin to think, feel and respond like the other, so much so that they can act on one another's behalf (Lewicki and Bunker, 1996). Lewicki and Bunker described this stage as "a leap of faith, grounded in the conviction that the partner can be relied upon to be responsive to one's needs in a caring manner, now and in the future" (2006, p.1011) 


\section{Relational Trust}

Trust develops when relationships are characterized by honesty and reliability (Thornton, 2010). Trust takes on different forms in various social systems, one of which is called 'relational trust'. Relational trust is defined by Bryk and Schneider as the "connective tissue that binds individuals together to advance the education and welfare of students" (2003, p.44). It is formed through the mutual understandings that arise out of sustained associations among individuals, in this case, the Professional Leader and the team, each of whom are expected to behave in a professionally appropriate manner. Developing relational trust is particularly relevant in the ECE sector due to the close physical working relationship teachers have with one another.

Rodd described how "developing trust stimulates a cooperative team spirit" (2013, p.163), therefore it is the Professional Leader's role to consciously look for ways to cultivate closeness within the team, as it is this trusting relationship with each other that provides the impetus for teachers to strive for optimal performance individually and collectively (Bloom, 2003). Findings from Notman's research (2011) support this as concepts of trust building and relational connectedness permeated through this series of case studies on what makes successful leadership.

Research also showed that having a climate of trust and openness between a Professional Leader and the team promotes an exemplary teaching and learning environment for both teachers and children (Bloom, 2003; Notman, 2011). Maintaining trust amongst the team is important as the quality of interpersonal 
relationships between adults influences not only the confidence of the teaching team, but it significantly makes a difference with children's learning development and achievement (Hipp \& Huffman, 2010; Notman, 2011, Robinson, Hohepa \& Lloyd, 2009; Robinson, 2011). Robinson et al. summed it up clearly:

"Leaders who are able to build trust relationships are in a position to foster the inquiry, risk taking and collaborative effort that school improvement demands" (p.206).

Leadership qualities that engender relational trust.

Bryk and Schneider (2002) discussed leadership qualities that engender relational trust, and that "a serious deficiency on any one criterion can be sufficient to undermine a discernment of trust for the overall relationship" (p.23). The most basic of these qualities is respect, which is demonstrated primarily by listening and valuing the ideas of other people. Respectful conversations are characterized by a genuine sense of listening to what the other person has to say and by taking these views into consideration in subsequent actions. Even though people disagree, individuals can and should still feel valued if the other person respects their opinions.

The second quality is personal regard for others, where leaders earn trust by caring about the personal and professional lives of their team. This comes from the willingness of participants to extend themselves beyond what is officially required of them, e.g. as written in their job description or contracts, as a genuine expression care for someone else's well being. The team then feels cared about, and experiences "a social affiliation of personal meaning and value" (Bryk \& Schneider, 
2002, p.25). Such actions then invites reciprocation from other, therefore strengthening the relational ties between them.

Role competence is the third criterion on which discernments of trust are based, and it depends on how well leaders carry out their role. Though it is difficult to measure exactly how trust will be gained as each situation will require a different style or level of leadership competency, it is the "gross incompetence [that is] corrosive to trust relationships" (Bryk \& Schneider, 2002, p.25).

The fourth determinant of trust is personal integrity, which in a basic sense, relies on whether or not there is consistency between what a Professional Leader says and does. This reliability is fundamental to advancing the basic instrumental aims of any collective activity (Bryk \& Schneider, 2002, p.26). Integrity also implies that a moralethical perspective guides one's work. This means that despite conflict arising amongst individuals within a community, a commitment to the education and welfare of children must remain to be the primary concern.

Bryk and Schneider (2002) explained the theory behind the development and the importance of relational trust quite clearly, however, they did not discuss specific leadership strategies used by participants involved in their study.

\section{Summary}

This literature review has discussed the definition of leadership within early childhood education. Though there have been much literature written about the 
definition and importance of building (relational) trust amongst the team (Brewster \& Railsback, 2003; Bryk \& Schneider, 2002; Lewicki \& Bunker, 1996; Stephenson, S., 2009; Tschannen-Moran \& Hoy, 1998), this review failed to generate any sources that discuss explicit leadership conceptual understandings and practices a leader can use to build and strengthen the relational trust, particularly within an ECE context. This is a substantial gap in research, which this study intends to bridge. 


\section{Chapter Three}

\section{Methodology}

This chapter outlines the design of this research study, selection of participants, ethical issues that were considered, as well as how data were collected and analyzed.

\section{Research Design}

This research took form of a case study within an interpretive research paradigm, as I was interested in learning ways I, as a Professional Leader, could strengthen the relational trust between the team and I.

Neuman (2003) states that an interpretive research paradigm is the "foundation of social research techniques that are sensitive to context, that use various methods to get inside the way others see the world, and that are more concerned with achieving an empathetic understanding that with testing laws of human behaviour" (pp.80 81). For interpretive researchers, the goal is to explore and discover how people experience daily life, make sense of their world, and the way they assign meanings to it (Neuman, 2003).

This research involved "collecting data from people, and about people" (Punch, 2009, p.276) hence ethical implications were considered and are discussed later. 


\section{Selection of Participants}

The research participants involved were the team of nine teachers from the centre I currently work in, as the focus of this study was to learn about leadership practices and conceptual understandings I could utilize that would help strengthen the relational trust between myself and the team.

Only eight out of the nine teachers responded to the first data collection (an online survey).

It is also important to note that a teacher resigned in between the time two data collection sources were distributed - the first and second survey - and a new teacher joined the team consequently. Nonetheless, still only eight teachers responded to the second online survey. It is unknown whether it is the same eight teachers who responded or not.

\section{Data Collection}

Data were collected from four different sources - two online surveys, professional conversations, four observations, and anecdotes from my personal journal.

\section{Online Surveys}

The first set of data were collected through an online survey via a website called Qualtrix (See Appendix A). A second survey (See Appendix C) was distributed approximately six months after the first survey, to determine if their views have changed over time. 
The purpose of these surveys was to gather information from the teachers about their thoughts, beliefs and perceptions of what an ideal leader is (Johnson \& Christensen, 2014). The surveys sought to discover skills, attitudes and values they see as important for a leader to have. Both surveys had three sections - Professional Relationship, Trust in my Leadership, and Professional Growth - and composed of a mixture of multiple-choice questions, rating scales, dichotomous questions and comment/essay box questions.

The second survey had two parts. The first part of the second survey mainly served as a 'follow on' from the Professional Conversations, as well as a check for any point of differences between participants' responses since the first survey. The second part of the survey was inspired by a 360-degree feedback questionnaire sourced online (http://www.appraisal360.co.uk) and consisted of twenty-three (23) 'yes' or 'no' statements about my leadership practice. Participants had the option of commenting afterwards to explain their choice.

\section{Professional Conversations}

"Informal Conversational Interviews" (Johnson \& Christensen, 2014, p.233), or as I termed it, "Professional Conversations" were conducted approximately 5 months after the first survey was carried out and analyzed. The interview protocol (see Appendix B) had three sections: general questions about leadership, questions about relational trust, and specific questions about my leadership practice. Each section had between two to five sub-questions. It was partly based on analysis of responses 
from the first survey. These professional conversations aimed to discover whether data between sources would be similar or not.

Professional Conversations were conducted after each teacher's appraisal/performance review and took between 30mins to an hour. The length of the conversation was dependent on how detailed the participant answered each question. Professional Conversations were audio recorded. I also wrote notes during the conversation, which I referred to during data analysis to compare accuracy with the conversation's transcript and utilized as documentary information (Yin, 2003). The Professional Conversations were professionally transcribed.

\section{Observations}

I asked our centre owner, whose professional knowledge and expertise is in the area of leadership in early childhood education (ECE), to observe me lead two staff meetings. I also asked her to observe me working/teaching 'on the floor'/alongside the team on two separate occasions. During these times, I asked her to specifically observe and give feedback on the way I communicated, both verbal and non-verbal (including body language and facial expressions), as well as the way I related with the team. Through these observations, I aimed to discover habits/practices I may or may not be aware of, that could either support or hinder my goal of strengthening the relational trust between the team and myself. 
Personal Journal

I maintained a journal, with brief anecdotes of my daily leadership experiences while I trialed strategies that were not only research from a variety of literature, but were also in response to formal findings gathered from this study's data collection. This journal allowed me to become reflexive and reflective. It also allowed me to chart my development as I faced challenges, learned new skills and came to new understandings (Mutch, 2013). This journal also became an "audit trail" which allowed me to document key decisions and the rationalizations for these (Mutch 2013).

These different data sources provided me a triangulation of different perspectives on my leadership practice.

\section{Ethical Considerations}

As the focus of this study was on discovering leadership practices that would help strengthen my relationship with the teachers I work with, my Centre was the most appropriate place to conduct this research.

After reading through Mutch's list of "advantages and disadvantages of working in your own settings" (2013, p.84), I carefully considered all possible ethical issues that may arise due to my decision to conduct this study at my place of work. While it was easy to fit my research alongside my Head Teacher duties as I already have the intimate knowledge of the Centre, as well as have an existing/established relationship with the participants, I knew prior to beginning this study that I would 
face challenges such as role conflict; possible lack of objectivity; and discovering things about/from my colleagues l'd rather not know. The latter proved true when it was time to code and analyze data.

The participants of this study were informed personally, as well as in writing (See Appendix D), of the purpose and nature of the study - that the focus was solely on my leadership practice and not about them/their practice - and allowed the participants to make an informed decision whether or not they wish to participate. Each teacher was given a consent form detailing what would be involved if they chose to participate in this study (see Appendix D).

The participants were assured that they had the right to withdraw until the end of the data collection period and that they were not coerced to participate simply because I am in a position of power (Mutch, 2013). The strictest of confidentiality and anonymity was practiced to honour the participants' privacy and safety.

Each participant was assured, in writing via the consent form (See Appendix D), and again in person, before our Professional Conversation started, that any information collected would strictly be used for this research, and would not influence nor affect our professional relationship in any way. For any questions or concerns about participating in this study, I asked that they speak with me about it in the first instance. However, if they were uncomfortable about approaching me directly, a 'contact person', who gave consent to take on this role (See Appendix E) was designated for participants to go to should they have any concerns about my work, 
i.e. role conflict between my role as the Centre's Professional Leader, and as a researcher, as a result of undertaking this research.

Victoria University Human Ethics Committee who ensured that all ethical considerations were met approved this research.

\section{Data Analysis}

While there is a wide range of approaches to the analysis of qualitative data, thematic analysis was the method employed to analyze this study's data. Thematic analysis aimed to identify overarching patterns, themes or concepts within the data (Punch, 2009). The first step of data analysis involved careful reading and re-reading of the data, to become thoroughly familiar with the material, and be immersed in the minute details of what was said, and what was portrayed through the data (Denscombe, 2007). During these meticulous readings, data were 'opened up' through coding. Key concepts and phrases were identified and reviewed and meanings were attached to the pieces of data by assigning codes or categories to the words and chunks of text. The next step in the analysis involved organizing data through axial coding by scanning the initial concepts for patterns and themes. Constant comparisons between data were made, and relationships among similar categories were examined and organized into overarching themes.

Data collected contained a mixture of positive and negative feedback. Though I appreciated the positive feedback, I found myself focused too long on the negative ones. It was overwhelming to say the least, reading about what my colleagues 
thought of my leadership practices. It brought about a sense of self-doubt and uncertainty as to whether or not I was even fit to be a Professional Leader, to the extent of almost giving up on this research. Many weeks were spent reflecting and processing this feedback.

Through confidential conversations with our centre owner, who also conducted observations of my leadership practices as part of my data collection, as well as with my thesis supervisor, I was able to unravel my many thoughts and gained clarification and better understanding of what these data possibly meant. It took me at least three months to be able to 'zone out' of all data gathered and not take it personally so I could translate these findings without any tainted interpretation.

Professional Conversations were professionally transcribed. Transcripts of their conversation were offered to participants. A tabled synopsis detailing each participant's summarized response to every interview question was created (See Appendix $\mathrm{F}$ for an example) and provided an easier and clearer way of analyzing data thematically. 


\section{Chapter Four}

\section{Findings}

The aim of this research was to investigate leadership conceptual understandings and practices that help strengthen the relational trust between a Professional Leader and her team.

In this chapter, findings are presented in order of when data were gathered - that is first survey, professional conversations and second survey. Next, findings from observations that were conducted over a three-month period are discussed. Finally, relevant entries collected from my personal journal that transpired over a six-month period are examined, where they captured significant development in my conceptual understanding of leadership as I grew into the Head Teacher role.

\section{First Survey}

The first survey (see Appendix A) was conducted through Qualtrix and had three sections: Professional Relationships, Trust, and Professional Growth. It was created to learn about the participants' perception of our professional relationship; to find out whether or not participants had trust in my leadership abilities at the time the survey was distributed; and to discover whether or not they felt they are growing professionally with me as the Head Teacher. Eight out of nine teachers in the team participated in the survey. 
As the survey was completely anonymous, participants' answers are referenced in quoted italics in this chapter.

\section{Professional Relationship}

The participants were given the options of 'Excellent', 'Very Good', 'Good', 'Fair' and 'Poor', and their responses are listed below (See Table 1.1).

\begin{tabular}{|l|l|}
\hline \multicolumn{2}{|l|}{$\begin{array}{l}\text { Table 1.1: How would you describe our } \\
\text { professional relationship since I became } \\
\text { the Head Teacher? }\end{array}$} \\
\hline Answer & Response \\
\hline Excellent & 1 \\
\hline Very Good & 3 \\
\hline Good & 4 \\
\hline Fair & 0 \\
\hline Poor & 0 \\
\hline
\end{tabular}

Findings revealed that communication was important to having a good professional relationship. Participants' comments are presented in Table 1.2

Table 1.2: How would you describe our professional relationship since I became the Head Teacher?

\begin{tabular}{|l|l|}
\hline Participant & Response \\
\hline 1 & $\begin{array}{l}\text { I feel I can talk to you about anything and if you are able to help me I } \\
\text { feel you will. We can always have a laugh together and I really value } \\
\text { that... }\end{array}$ \\
\hline 2 & $\begin{array}{l}\text { We have always worked well together. We have mutual respect and } \\
\text { are very similar. }\end{array}$ \\
\hline 3 & $\begin{array}{l}\text { I feel we are open and honest and that we communicate well } \\
\text { together. I think we have a great professional relationship. }\end{array}$ \\
\hline 4 & $\begin{array}{l}\text { We have good communication and will address matters as they arise. } \\
\text { able to effectively communicate with each other. }\end{array}$ \\
\hline 5 & $\begin{array}{l}\text { I feel like we are able to have professional discussions and the } \\
\text { occasional courageous conversation while still maintain our }\end{array}$ \\
\hline
\end{tabular}




\begin{tabular}{|l|l|}
\hline & $\begin{array}{l}\text { professional relationship. In general I feel supported and able to } \\
\text { support on occasion. }\end{array}$ \\
\hline
\end{tabular}

Although I had been working at the centre for three years prior to the study, I had just been promoted to the role of 'Head Teacher' when it began. Hence, this study aimed to find out whether participants sensed any changes in our professional relationship due to this promotion. Six participants perceived that our professional relationship "somewhat changed" since I became the Head Teacher, out of the choices of answers of 'To a great extent', 'Somewhat', 'Very little', 'Not at all' (See Table 1.3).

\begin{tabular}{|l|l|}
\hline $\begin{array}{l}\text { Table 1.3: Since becoming the Head } \\
\text { Teacher, has our professional } \\
\text { relationship changed? }\end{array}$ \\
\hline Answer & Response \\
\hline To a great extent & 0 \\
\hline Somewhat & 6 \\
\hline Very little & 1 \\
\hline Not at all & 1 \\
\hline
\end{tabular}

Participants were asked how they believe our relationship had changed, and their responses are listed below (See Table 1.4).

Table 1.4: In what ways has our professional relationship changed (if it did)? Response

1. I've just had to learn about your style of leadership.

2. We have more complex conversations and work closer together.

3. I guess so, in the way that we discuss and talk about different thing now...

4. We talk more often. You ask me how I am doing on a regular basis (at least once a day) you have time to hear me out and try to understand my point of view...

5. As we don't work quite closely as we used to (i.e. not in the same space) I find that I have to really make sure that I put in the effort to catch up and make sure that I 
touch base regularly.

6. There are opportunities for us to have professional discussions and share our thoughts and ideas.

The study aimed to find out what traits or characteristics teachers believe is important for a leader to have. Participants were asked to select five traits out of a list of 40 "traits we associate with good leaders" (Bloom, 2010, p.37) (See Appendix A). Findings showed that traits selected by most included 'trustworthy', 'collaborative', 'honest', 'objective', 'passionate', 'open', consistent', 'ethical', 'inspiring' and 'responsible'.

Being a 'good listener' and being 'respectful', however, were selected almost by all as important traits a leader should have (See Table 1.5).

Table 1.5: From the list (see Appendix A), please select five traits you believe is important for a leader to have.

\section{Response}

1. Assertive, good listener, problem solver, enthusiastic, ethical. (I think all of the above are important, this was hard)

2. Trustworthy, visionary, inspiring, inquisitive, collaborative, respectful. Sorry I cannot pick only 5 ! But if you have to, take out inquisitive.

3. Honest, responsible, respectful, objective, good listener.

4. Confident, inspiring, respectful, patient and passionate

5. Respectful, trustworthy, open, passionate, ethical

6. Ethical, compassionate, decisive, fair, consistent

7. Respectful, good listener, inspiring, open, collaborative

8. Respectful, responsible, consistent, good listener, flexible

When asked whether they think I possess "All (5 traits)", "Most ( $3-4$ traits), "Some (1 - 2 traits)", or "None" of the traits they previously identified, seven out of eight participants answered "Most (3-4 traits)". The survey did not seek specifically which traits they believed I possess (See Table 1.6). 


\begin{tabular}{|l|l|}
\hline \multicolumn{2}{|l|}{$\begin{array}{l}\text { Table } 1.6: \text { Do I possess the traits you've } \\
\text { identified? }\end{array}$} \\
\hline Answer & Response \\
\hline All (5 traits) & 1 \\
\hline Most (3-4 traits) & 7 \\
\hline Some (1-2 traits) & 0 \\
\hline None & 0 \\
\hline
\end{tabular}

\section{$\underline{\text { Trust in my Leadership }}$}

The next sets of questions were aimed to find out about their trust in me as Head Teacher. In a scale of $1-5$, with 1 representing "I don't trust you" and 5 representing "I trust you a lot", the survey averaged a result of 3.75 as the teachers' collective level of trust in me at the time this data was gathered (See Table 1.6).

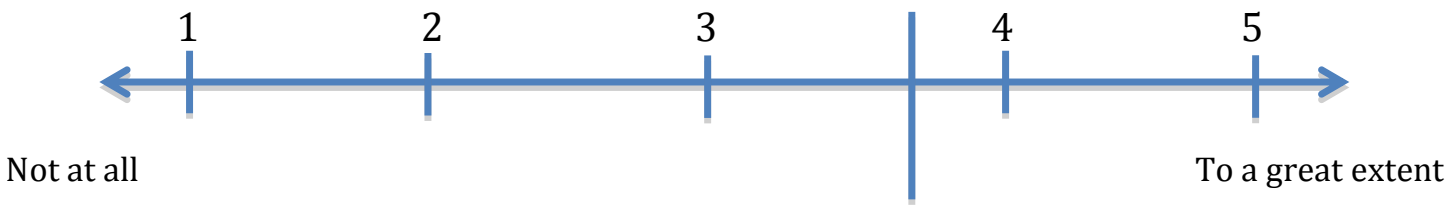

Table 1.6

Participants were asked to choose as many as they deemed relevant out of the seven choices of responses provided to describe ways I have gained their trust by this point in time (see Appendix A). Findings showed that participants have gotten to know me quite well over time; that they feel respected and valued by me; that I am always available for a chat; and that I am able to support them with their professional goals as the ways in which I have gained their trust (See Table 1.7). 


\begin{tabular}{|l|l|}
\hline $\begin{array}{l}\text { Table 1.7: In what ways have I gained your level of trust? (Can choose more than } \\
\text { one) }\end{array}$ & Response \\
\hline Answer & 7 \\
\hline I've got to know you quite well over time. & 2 \\
\hline $\begin{array}{l}\text { You are reliable. You keep your word, i.e. you'll do what you say } \\
\text { you'll do }\end{array}$ & 5 \\
\hline You support me well with my professional goals & 3 \\
\hline $\begin{array}{l}\text { You keep me well informed and include me in decision making when } \\
\text { necessary }\end{array}$ & $\begin{array}{l}\text { You are open and honest, and provide constructive feedback when } \\
\text { needed }\end{array}$ \\
\hline You are always available for a chat. & 5 \\
\hline I feel respected and valued by you. & 6 \\
\hline You're a good listener. & 3. \\
\hline Other. & 0 \\
\hline
\end{tabular}

Participants were then asked for suggestions on how I could further gain their trust

(See Table 1.8). Findings identified three ways I can do this - by being assertive; by

being consistent; and by being accountable.

\section{Table 1.8: Suggestions how I can gain your trust (further) as a Head Teacher? \\ Response}

1. Sometimes I would like to see you be more assertive with other teachers so that the work load across the team is more even, however I do understand that you have more background knowledge on the other teachers lives.

2. If we ask you to do something and you do not have time in that week pass it back - it would mean more to us that you admit that than forget about it. Be accountable with your time. We don't know what you o in the office all day but you are always 'busy' (although never too busy to listen which is good).

3. Follow through in a timely manner when you agree to be somewhere or do something. Be accountable when this does not happen. Ensure consistency and fairness with your expectations of team members.

4. Spending a little bit more time on the floor (when possible) so that when teachers need support with particular things, e.g. flow of the day, programme planning etc, you have first hand experience in what we are talking about.

5. Continue to communicate

6. Consistency/decisiveness and a slightly more assertive (when necessary) demeanour. 
7. This will take time.

8. None.

It was suggested that I have a "slightly more assertive (when necessary) demeanour", especially when ensuring an even distribution of workload across the team. This was based around the time when a couple of teachers in the team were stepping away from some responsibilities (see Personal Journal Entry later in the chapter) due to a variety of personal reasons. This related well to another participant's suggestion of being more consistent - "ensure consistency and fairness with your expectations of team members". The last suggestion is for me to be more accountable - see response 3 in Table 1.8.

\section{Professional Growth}

I believe that one of my roles as Professional Leader is, to encourage the learning and development of "professional potential" (Rodd, 2013, p.166) of each individual teacher. Hence one of this study's aims was to find out whether they feel there are growing professionally with me as the Head Teacher, e.g. do I motivate/challenge/inspire them. This was framed as a 'yes' or 'no' question, to which all participants responded with 'yes', I motivate/challenge/inspire them professionally.

When asked how, four participants explained that I challenge them out of their comfort zone, which consequently results to their professional growth. As one teacher explained: 
"You do a great job at pushing me to extend myself and work outside of my current comfort level. You manage to do this while not pushing me too far outside my level of comfort.."

This was consistent with a brief journal entry I wrote about how I was figuring out a way to gently challenge a teacher, without pushing her too far that she'll think the task was hard. This is discussed later in the chapter.

Other participants' responses were as follows:

Table 1.9 : How do I motivate/challenge/inspire you professionally? Response

1. (Centre) as a whole has helped me grow professionally. You have made me think about doing things I didn't think I could do before.

2. I find your passion and ability to get things happening inspiring - especially with Reggio Emilia practices.

3. Yes. Opportunities to support you in your role are beneficial for me as a growing leader.

4. You support me with my professional goals, share your knowledge and encourage/motivate me to continue my own learning and reach my goals.

5. I am understood and acknowledged.

6. I feel as though you are able to challenge and motivate the teaching team. I know that I have stepped out of my comfort zone a lot while you have been head teacher, although I do sometimes worry that the expectations are not always manageable.

7. I find your teaching style inspiring. Especially (and probably more relevant for this) your ability to remain calm under pressure/stress and still rely on our well established systems and make a plan. You remind us all that we do have systems in place for every situation and support us to fall back on those systems even when it feels overwhelming.

8. You challenge my thinking.

This study also aimed to discover if there is something within my leadership practice that I can/should improve or change so I may gain their trust further. Seven out of eight participants answered 'yes'. It was suggested that I "include others more in 
making decisions" while at the same time ensuring that I action and ultimately make the final decisions as the Head Teacher. I personally found this a challenge, as one teacher have picked up and commented on:

"I sometimes get the feeling that you might be worried about upsetting people and that can lead to a lack of action. You are great at setting a line between friendship and professional relationships and I think you should trust yourself in that more".

\section{Professional Conversations}

Professional Conversations were conducted in March 2016, approximately 5 months after the first survey was carried out and analyzed. The interview protocol (see Appendix B) is in part based on analysis gained from the first survey. These professional conversations aim to discover whether data between sources would be similar or not. Nine individual interviews were conducted separately. Pseudonyms are used in this section to ensure participants' anonymity.

Post coding and analysis of the interviews highlighted three leadership skills participants perceived as important for a Professional Leader: Being available and approachable; listening; and communication. Findings showed that teachers believe it is through the demonstration of these skills can a Professional Leader gain the team's trust. 
Being Available and Approachable

The need for a Professional Leader to 'be available and approachable' was strongly evident across all conversations. Availability and approachability was a shared, consistent response amongst participants when asked about responsibilities and traits they believe a leader should have. As Rebecca shared, "I expect you to be there when I need to talk to you...to be available...I should be able to come to you about anything at any time..."

Six out of the nine participants also mentioned in one way or another that the Professional Leader's ability to be available and to be approached when needed was also a contributing factor to the development of their trust in the Professional Leader. For example, Cara, similar to Rebecca's sentiments, talked about how she needs to trust that I am available for support if and when she needs me for whatever purpose it may be. This sense of trust consequently deepens when the Professional Leader has been available when needed because -

"You feel you're listened to when you to talk to your leader, then you know through that you gain trust because you feel like you've been heard..." (Cara)

Cara went on to explain that trusting the Professional Leader's availability for support has strong implications for one's wellbeing.

"It has an effect on your, like, in terms of my wellbeing as well because I know I can trust you, I can approach you about anything so I'm not holding onto things that could worry me or concern me or you know, affect my own wellbeing" (Cara) 


\section{Listening}

Consistent with findings from the first survey where participants identified being a 'good listener' as a trait they believe a Professional Leader should have. Following on from being available and approachable, Sarah explained that it is through listening that a Professional Leader can gain her trust. She explained listening as "...taking your feelings seriously". Sarah went on to explain that if "I saw someone opening up to you, and you were just kind of blasé about it and not really listening, it kind of just deter you from wanting to open up..."

Louise also talked about how a Professional Leader can gain her trust by listening "Listening about what has actually happened rather than assuming..." This signaled the importance of gathering, or listening to all information first before making any assumptions about anything, particularly if there is conflict involved. Rebecca shared this view, and indicated that a Professional Leader "need to be able to listen...actively listening..."

To actively listen meant being able to pose questions and facilitate 'learning in the moment'. This is something that Cara appreciated and as a result -

"...You're aware of what my goals are and help me work toward them...you help me grow but not give me the answers...you help me to lead my own learning..." 


\section{Communication}

The ability to effectively communicate was another key leadership skill that influences the team's trust in the Professional Leader. Regular 'catch ups' initiated by the Professional Leader were something that the participants really appreciated, and that it was a great way for a Professional Leader to gain the team's trust. Holly explained "even if it's just a couple minutes on a lunch break, to see how the day's going and I think, on daily kind of perspective that's really helpful, you know, you're showing that you care about us".

With nine teachers in the team, Louise asserted that not only does a Professional Leader need to have strong communication skills but there is also the need to have the "understanding of the way you communicate as a leader (and) the different ways that other people (like to) communicate too" is important.

Robyn specifically appreciated the way the messaging feature on our online learning documentation and assessment system, StoryPark ${ }^{T M}$ has been utilized as a communication strategy. Vital messages and information that all team members need to know are sent out like an email via StoryPark ${ }^{T M}$, which ensures everyone receives the same message at the same time. As Beth explained it, by "communicating consistently across the team, there isn't any, you know, like gossip I guess that goes on, where messages have been mixed or something's been said to someone that hasn't been said to someone else..." trust is gained by the Professional Leader. 


\section{Participants' understanding of the term 'Relational Trust'}

This study also aimed to discover participants' understanding of the term 'relational trust', and to see whether it matched with how literature has defined the term.

Below is a tabled response of each participant to the question,

\begin{tabular}{|c|c|}
\hline Participant & Response \\
\hline 1 & $\begin{array}{l}\text {-Trust my feelings are valued } \\
\text {-Having faith in somebody } \\
\text {-Knowing that you are taken seriously } \\
\text {-The information you give is respected and confidential }\end{array}$ \\
\hline 2 & - Keeping confidential information confidential for you. \\
\hline 3 & $\begin{array}{l}\text {-Knowing you can share your thoughts/ideas and talk to } \\
\text { someone and its not going to affect the professional } \\
\text { relationship that you have. }\end{array}$ \\
\hline 4 & $\begin{array}{l}\text {-Trust that goes both ways } \\
\text {-'Relational' is about relationship and that its open and } \\
\text { honest and you can't hold grudges } \\
\text {-I should be able to come to you about anything and trust } \\
\text { that you will be there } \\
\text {-You trusting us to our job and carry out what's important to } \\
\text { you as well } \\
\text {-Involves being on the same page } \\
\text {-If we disagree with you then we need to be able to have } \\
\text { those conversations about it }\end{array}$ \\
\hline 5 & $\begin{array}{l}\text {-Listening } \\
\text {-Being heard and supported to take just whatever steps are } \\
\text { right }\end{array}$ \\
\hline 6 & $\begin{array}{l}\text {-Being able to trust each other to complete your role } \\
\text {-You trusting me to follow through when you ask me to do } \\
\text { something and I've said I'll do it } \\
\text {-Me being able to come to you }\end{array}$ \\
\hline 7 & $\begin{array}{l}\text {-When someone says they're going to do it, they do it } \\
\text {-Trusting other people in the team to get things done } \\
\text {-They've got your best interests/children's interests } \\
\text {-Trust you have in relationships } \\
\text {-Takes a long time to build up }\end{array}$ \\
\hline 8 & $\begin{array}{l}\text {-How comfortable you are to approach each other } \\
\text {-Confidence to express our true feelings, whether that be } \\
\text { positive or negative } \\
\text {-Trust we're there } \\
\text {-Trusting that you're there to support me and that you're }\end{array}$ \\
\hline
\end{tabular}




\begin{tabular}{|l|l|}
\hline & available \\
\hline 9 & $\begin{array}{l}\text {-Having the relationship within the team, with each member } \\
\text { of the team } \\
\text {-Being able to tell someone really anything that's on your } \\
\text { mind } \\
\text {-Knowing that they'll be there no matter what } \\
\text {-They're not going to tell anybody what you've talked about }\end{array}$ \\
\hline
\end{tabular}

Thematic analysis of participants' responses show that collectively the team understood relational trust to be about the Professional Leader being available and "being there", whom team members can come to and be approached in times of need, to listen and to support. Relational trust "goes both ways" and that its about "trusting each other to complete your role", "to get things done". It is also about confidentiality - not telling anybody else information that's been shared in confidence.

\section{Second Survey}

The second survey (see Appendix C), also conducted through Qualtrix, was distributed in April 2016, six months after the first one. It is important to note that one teacher had gone maternity leave, and a new teacher had joined the team by the time the second survey was released. Eight out of nine teachers participated. It is unknown whether or not it is the same eight teachers who participated in the first survey due to its anonymity. As with the first survey, participants' answers are referenced in quoted italics. 
The second survey had two parts. The first part of the second survey served as a follow on from the Professional Conversations, as well as a check for any point of differences between participants' responses since the first survey.

Since the first survey, I had been utilizing and trialing different leadership strategies. This was in response to, not only the formal findings gathered from this study's data collection, but also to personal lessons I have learned along the way as I grew more into the Head Teacher role. Therefore, the second survey was also designed to determine whether strategies I have applied were effective or not in strengthening my relational trust with the team.

The second part of the survey was inspired by a 360-degree feedback questionnaire sourced online (http://www.appraisal360.co.uk) and consisted of 'yes' or 'no' statements about my leadership practice. Participants had the option of commenting afterwards to explain their choice.

Part 1:

This part of the survey consisted of three sections, similar to the first survey: Professional Relationship, Trust in my Leadership, and Professional Growth.

\section{Professional Relationship}

The second survey aimed to find out whether or not my professional relationship with each participant has changed in the last six months, since the first survey was 
distributed. Findings showed that the participants perceived its changed "somewhat", with some saying "not at all", when given the options of 'To a great extent', 'somewhat', 'very little' or 'not at all' (See Table 3.1).

\begin{tabular}{|l|l|}
\hline $\begin{array}{l}\text { Table 3.1: Has our professional } \\
\text { relationship changed in the last six } \\
\text { months? }\end{array}$ & Response \\
\hline Answer & 1 \\
\hline To a great extent & 3 \\
\hline Somewhat & 1 \\
\hline Very little & 3 \\
\hline Not at all & \\
\hline
\end{tabular}

When asked how it had changed, participants' comments such as "We understand each other better" and "Working/planning more collaboratively" indicated a growth in our professional relationship. One comment in particular confirmed that the strategies I have been applying in recent months has been effective and has contributed to the positive change in our professional relationship - "You have taken on comments from the last survey and changed your practice slightly which has increased my confidence and respect in our relationship".

This study also aimed to find out whether or not there were any changes in participants' response, in comparison to the first survey, and the professional conversations, when asked for at least three traits they believe a Professional Leader should have. No list was given, unlike in the first survey. In this instance, common answers provided by participants were: 'Good communicator/communication', 
'Trustworthy', 'Honest' and 'Respectful'. See Table 3.2 for other qualities noted by participants.

\begin{tabular}{|l|}
\hline Table 3.2 : Identify at least three traits you believe a Professional Leader should have \\
\hline Response \\
\hline 1. Knowledge, understanding, humour \\
\hline 2. Good communication, reliable, trustworthy \\
\hline 3. Approachable, open, honest, respectful but able to be assertive when needed \\
\hline 4. Open communication, compassion and professionalism \\
\hline 5. Passion, people skills, organised \\
\hline 6. Trustworthy, great communicator, positive role model \\
\hline 7. Respect, vision, humility \\
\hline 8. Honesty, consistency, listening \\
\hline
\end{tabular}

\section{$\underline{\text { Trust in my Leadership }}$}

This constructive change in our relationship seemed to equate a growth in their trust in me as the Professional Leader. When asked as a multiple choice question, whether their trust has grown or lessened in the last six month, six participants indicated that "it has grown", whilst two participants chose "it hasn't changed". No one chose the third option which was "it has lessened" (See Table 3.3).

\begin{tabular}{|l|l|}
\hline $\begin{array}{l}\text { Table 3.3 : Has your trust in me as a } \\
\text { Professional Leader grown or lessened in } \\
\text { the last six month? }\end{array}$ \\
\hline Answer & Response \\
\hline It has grown & 6 \\
\hline It hasn't changed & 2 \\
\hline It has lessened & 0 \\
\hline
\end{tabular}

It appeared that time was a factor in the development of their trust in me - time to get to know me and understand my leadership style, which was similar to findings from the first survey. As one participant commented, 
"I have gained more understanding of you as a leader and your expectations and this has increased my trust in you"

When asked for ways I can gain their trust further, two main ideas were collectively proposed - that I (continue to) maintain open and reciprocal communication, and that I "follow through with actions and conversations". The latter was consistent with findings from the first survey. Accountability and following through is also a specific recommendation from one participant, so I may grow further and become a better Professional Leader - "More accountability across the team... so your expectations (are) clear..." It seems being able to follow through is a skill Professional Leaders should have in order to gain the team's trust.

\section{Professional Growth}

A similar question was posed in the first survey about participants' perception of whether or not they feel they are growing professionally with me as the Professional Leader. In this second survey, the question was more about whether they feel they have grown professionally in the last six months with my leadership since the first survey was distributed. This question was intentionally reflective of my application of different leadership strategies I have mentioned earlier.

Findings showed that, through my encouragement and "support to take baby steps in my own time", via a 'yes' or 'no' question, all participants responded 'yes' they have grown professionally with me as the Professional Leader. One participant commented how I was "encouraging of my (her) own professional goals and allow 
me (her) opportunities to practice these skills where appropriate". Two participants explained that through my encouragement, they have taken on extra responsibilities and explored new ideas, consequently growing their confidence as a result - "I (now) have confidence in myself within the (centre) environment and my ability to influence the environment which I work in".

\section{Part 2:}

This part of the second survey, inspired by the 360-degree feedback questionnaire sourced online (http://www.appraisal360.co.uk), consists of six leadership competencies: Communication, Developing Others, Integrity, Motivation, Relationship Building and Team Work. Each competency comprised of $3-5$ statements each pertaining to my leadership practices (See Appendix C). Each statement asked for either a 'yes' or 'no' answer. Further comments explaining their response were optional.

\section{Communication}

All eight participants responded 'yes' to the statements regarding my communication skills. The statements were:

- I (Professional Leader) ask questions to find out your real views and to check whether I understood your right.

- My manner of communication, style and presence gives you a positive impression.

- I listen to and consider your views and perspectives.

- I state my own views/ideas clearly and concisely. 
- I handle disagreement constructively.

An analysis of their responses tells me that they believed I communicate well "...I find your communication style to be very open and welcoming." "You communicate your own ideas clearly and honestly..." "You explain your views with passion in a clear way".

However, questions whether I listen enough surfaced "I feel like you have a solution or answer before asking enough questions to work out what is actually being said or asked"

"Sometimes I feel you jump to the defense of others rather than accept my point of view"

"It can occasionally feel as though you are asking for our feelings and ideas on a matter already knowing what changes you are going to make"

It appears that though I communicated my ideas clearly, I needed to work on my listening, and perhaps even my questioning skills, further.

\section{Developing Others}

'Yes' was the unanimous response to the three statements pertaining to my competency of developing others professionally. The statements were:

- I create and inspire a positive learning environment.

- I encourage you to (continuously) challenge yourself professionally. 
- I coach and mentor you according to your strengths, as well as your aspirations.

Consistent with previous data collected, through gentle encouragement and support of each team member's individual professional goals, participants felt they have grown a lot as a teacher with my leadership. One teacher summed it up:

"I feel that I have grown a lot as a kaiako (teacher) over the last year and you have been incredibly supportive. I feel like I have taken on a lot more responsibilities and I am really enjoying it so thank you for your encouragement, trust and belief in me."

Further analysis of their responses indicated that my commitment to continued learning (e.g. by undertaking this research) inspired the participants to challenge themselves further.

"You lead by example, with your studies and continued learning yourself"

"You are always learning yourself and encouraging others to learn too" "You gently push me to think deeper or a different way"

$\underline{\text { Integrity }}$

All participants responded with 'yes' with regards to my integrity. The statements were:

- I take and accept responsibility for my own work and decisions.

- I admit when I've made (a) mistake/s. 
- I stick to decisions that have been made (by me or by the team) and stay true to my word.

- I am fair and use my positional power with care and restraint.

Not many comments were provided to further explain their answers. However, the few comments gathered and analyzed indicated findings consistent with earlier collected data. The need for accountability and better follow through were evident in the following feedback:

"...Sometimes you do not do the things you say you will (mainly having conversations with people) and it can be frustrating if these conversations are then delegated to someone else..."

"I think sometimes you find conflict or being firm and consistent difficult. This means that sometimes you don't follow through with a plan or best course of action"

\section{Motivation}

All four statements relating to my skill of motivating others received with an undisputed 'yes' response. The statements were:

- I believe in your abilities.

- I give you praise and open (public) recognition.

- I have the knowledge, experience and maturity to support you (individually) and the team (as a whole) through difficult circumstances.

- I motivate and inspire you through personal example (role modeling). 
Feedback were consistent with those provided earlier under the competency of 'developing others', as is evident from this particular comment:

"You are always encouraging...you hold a strong sense of trust in our abilities"

One particular comment, which related to supporting the team through difficult circumstances, echoed findings from the first survey about ultimately making the final, though hard, decision as the Professional Leader.

"This can be a balancing act - especially when you are a naturally empathetic person. I think you do very well trying to manage the various circumstances and life challenges amongst the team. Sometimes the hardest things to say or do, can also be the best"

\section{Relationship Building}

All participants responded with 'yes' when asked about my relationship building skills with the team. The statements were:

- I bring tensions (i.e. between teachers) to the surface, help to resolve conflicts (for example, by encouraging courageous conversations) and produce positive outcomes.

- I build/have rapport with people (team, children, families).

- I go out of my way to develop trust in relationships.

- I notice when you need help and support. 
Findings showed that 'catch up times' were highly valued with regards to building relationships with each teacher, and in particular, building that trust with one another.

"You show a lot of care towards everyone and always try to check in with everyone on a daily basis"

"Your daily catch ups really do help with this (developing trust)...You really take on board what the kaiako say to you and you do your best to make changes in a way that any issues brought to your attention are remedied as best as they can be"

Again, the need to make my voice as Professional Leader more evident was mentioned - "I feel a 'professional leader' voice needs to be more present in some situations" - especially during times of conflict.

\section{Team Work}

Three statements pertaining to teamwork all gathered 'yes' responses from the participants. The statements were:

- I develop ideas and solutions jointly with you and/or the team.

- I encourage a strong sense of team spirit.

- I focus the team on what will contribute to success (vision) in the long term.

Little feedback was provided to further explain their answers. However three comments were worth noting: 
"I would like to know more of what your long term plan is for (centre) as you are our leader and we will need to be on board to ensure it happens" "I enjoy your emphasis on team work and working together to find solutions that work for all of us"

"(Focusing the team) is a strength of yours"

It appears they perceived that I am skilled with encouraging the team to work together, and that sharing more of what my long-term vision is with the team would help strengthen this skill.

\section{Observations}

The owner of the centre conducted observations of my leadership practices over a period of three months. These included observations of my leadership and facilitation of two separate team meetings, as well as of two separate times when I worked alongside the teaching team within the programme ('on the floor'). This study aimed to discover, through these observations, habits or practices I may or may not be aware of that may influence the development of relational trust between the team and I.

Observations of my time spent 'on the floor' showed I communicated clearly with a number of teachers, mostly checking in with what was happening in different learning spaces. I coached and passed on information where necessary, which allowed teachers to take over what I was responsible for, before I moved on. An 
example of this was when I was handing over the teaching responsibility of an art experience I have set up in order to welcome a visiting family:

"Brigitte was at a table with magazine and scissors, joined by toddlers from Koromiko and Nikau groups. When A (child) arrived with her mother, Brigitte called to Katrina* and asked her to sit down with the children doing cutting. She explained what was happening, how Katrina could continue to support cutting, keeping children safe. She asked Katrina to also supervise the adjacent table where a 4-year-old had initiated using watercolours. Said that girl should be guided to clean up and put watercolours back on the art shelves when she'd finished. Katrina was asked to ensure art shelves were left attractive. Respectful tone." ("Pseudonym)

Observations of my facilitation of team meetings that were performed on two separate occasions showed that I needed to work on my adult teaching skills. Findings specifically from the first observation noted my lack of preparation to engender more reflective discussion amongst the team - "visibly had not thought who should have (done the task)". This unpreparedness was also noticeable non verbally, e.g. "uncertainty evident in body language".

\section{Personal Journal}

Over the six-month data collection period, I have kept and regularly wrote brief anecdotes of my learning experiences as I grew into the Head Teacher role. This formed my final data source. Two most utilized leadership skills were clearly evident 
in all entries, and that were communication and listening. Many journal entries also focused on inspiring professional growth amongst the team. One particular journal entry highlighted the significance of time management as a crucial leadership skill.

Excerpts from my journal are in italics.

\section{Communication}

A series of entries highlighted my awareness of clearly communicating my expectations. Participants shared this sentiment in the first survey where they suggested that I be more assertive and consistent with my expectations for every teacher to ensure there is an even distribution of responsibilities amongst the team. In the first entry I wrote about how after an analysis I did (as part of my Head Teacher role) of written assessment of children's learning I noticed Teacher A's lack of recent documentation of her key group of children's learning. The last piece of documentation she wrote was two months ago, which was unacceptable by our centre's standard. I knew she has had a challenging time lately, which possibly have contributed to this poor performance. Regardless "I will need to talk to her about my findings, and say that though I understand her situation right now, she still has a responsibility and she needs to figure out a solution that will ensure she produces the required paperwork..." (Entry dated 3.11.15) I spoke with Teacher A the following day, however, it did not go the way I planned it - "What happened next was that we talked more about her problems and challenges and by the end of it, though she 
seemed to appreciate 'my listening ear', I don't think we came to an agreed solution to the issue I raised, with was the lack of stories written" (Entry dated 4.11.15).

These entries indicated how I needed to work on communicating skills, specifically the ability to engage in "Open-to-Learning Conversations" (Robinson, Hohepa \& Llyod, 2009). Upon reflection, I had failed to clearly give my key message, which was the need for Teacher A to maintain her professional responsibility of documenting children's learning experiences in a timely manner, despite undergoing many life challenges at the same time. This poor performance went on for another week, which Teacher B eventually picked up on and spoke with me about. Along with the lack of documentation, Teacher B noticed Teacher A's insufficient contributions to the learning programme and wondered what Teacher A was doing during her noncontact time, when "...all these jobs should be done. I said to Teacher B that I am aware of what's happening with teacher $A$, and that I have spoken with her about this...that I know what's happening with her so I can sympathize... Teacher $B$ then went on to say that she thinks I'm too nice in letting her get away with it...(and that) 'Its not fair that she's not doing her fair share and other teachers 'pick up the slack' but I understand you know a bit more about the situation that I do'..." (Entry dated 12.11.15)

This particular conversation entry was really interesting to unpack. I re-read this entry and reflected on this moment many more times. I eventually realized that when Teacher B opened up the conversation, she never asked me for a response. She opened up our conversation by saying how she noticed what Teacher A's lack of 
documentation and her thoughts about what Teacher A should be doing during her non-contact time. She was sharing her observations of Teacher A's actions (or lack of). I jumped into conclusion, and responded what I thought she wanted to know or talk about. Perhaps she had it implied through her facial expressions, body language or the tone of her voice, however, she had not verbally asked for my thoughts or opinions about the matter. I quickly assumed without gathering further information from Teacher B first - Why was she asking? What was her concern? Consistent with findings from the second survey, it appears I need to improve both my listening, and questioning skills further.

This conversation in particular also highlighted the importance of maintaining consistent expectations amongst the team. Was the underlying message of the conversation more about the sentence 'Its not fair that she's not doing her fair share and other teachers 'pick up the slack'? Did Teacher B bring this issue up to call my attention to the unequal division of responsibilities? Upon reflection, I might have simply jumped into conclusion and defended Teacher A's performance, and not acknowledged the true issue at hand, which was the inconsistency of expectations amongst the team.

\section{Listening}

Another journal entry emphasized the need for me to better my listening skills. This time when Teacher $\mathrm{C}$ came into the office, visibly upset. She shared with me recent struggles she has been experiencing at work. Teacher $C$ was at a lost and did not know what to do. "...I knew what she was going through as I have been there many 
years ago, back in my first few years of teaching. I shared my experience and what I learnt, in the hope that she'll learn from my story too. She nodded along as I talked. She thanked me afterwards and said she felt better" (Entry dated 13.4.16).

In the moment, I believe I was being empathetic with Teacher C. I empathized with what she was going through, what she was feeling, because I have experienced the same situation in the past. However, as I thought about this conversation more, I realized that the topic went from Teacher $C$ sharing her worries, to me sharing my story, my "war stories" (Robertson, 2016). I had stopped listening to Teacher C, and continued on talking about my experience.

\section{Team's Professional Growth}

Many entries I wrote in my journal were about strategies I utilized to specifically promote professional learning amongst the team through mentoring and coaching, as part of my role as the Head Teacher. Key strategies were - 'regular vision reminder', and 'individualized professional learning'.

\section{Regular Vision Reminder}

One feedback I received from the second survey was that a participant wanted "to know more of what your long term vision is for (centre) as you are our leader and we will need to be on board to ensure it happens". Subsequently, in a personal conversation with Teacher D, after a particularly frustrating team meeting where I felt like the team "...zones in on the 'daily challenges', constantly complaining about what's going wrong everyday, instead of looking at the 'big picture'" (Entry dated 
22.3.2016), I was advised that I as the Professional Leader intentionally and frequently remind the teaching team of the centre vision so that the team may better understand why we were doing the things we were doing.

Teacher D further explained that I "...needed to help the team see the bigger picture too, so they too can focus more on that, than the daily challenges. If they are reminded of the vision, why we were doing the things we were doing, then the team will be more understanding and willing to cooperate towards the achievement of that vision" (Entry dated 22.3.2016). The underlined comment was a turning point in my understanding as a leader. From then on, I began to intentionally remind and highlight the word 'vision' during team meetings by "...saying the phrase 'It is my vision that....' ... and I think it is making a difference to teachers' perspectives. They seem to understand the purpose of the self-review and what our aims are. Each meeting has been successfully building on from the last one too, with each one helping us get closer to our goal, our vision..." (Entry dated 19.4.16).

Team discussions during meetings changed from complaining to reflecting as a result of my frequent reminder of the centre vision. By ensuring the vision was constantly in the minds of teachers, with the right reflective questions, they appeared to gain a sense of direction and focus towards the achievement of that vision.

Individualized Professional Learning

Right from when I began my role as the Head Teacher I knew my priority was to strengthen the relational trust between myself and the team. Therefore, I initiated 
the practice of 'regular catch ups' with each teacher so I got to know them better and develop our relationship further.

The first two entries narrate the time when I gently encouraged a teacher out of her comfort zone to present for the first time at a professional seminar.

First entry, 1.2.16 - "I checked up on Teacher E this afternoon to see how she was feeling in preparation for our upcoming seminar... She said she was incredibly nervous but will do her best to get through... I knew she was not keen on presenting at all. This was her first time presenting to a bigger audience...understandably she's anxious and unsure. However, I know she can do this... I know she's ready for the challenge. She knows the topic, the content so well that sharing her expertise to a wider audience is the next step in her professional development. And I told her exactly that. I said I believe in you you are ready."

Second entry, 23.2.16 - "Teacher E wrote me an 'appreciation note' at our team meeting tonight, which said that she appreciated the trust I had in her abilities to present and the support and encouragement l've given in the days coming up to the seminar day. She also said after the note was read out that it was just the right amount of push from me too, which she needed."

By having regular time to connect with each teacher, I began to learn and understand his or her professional and personal goals and aspirations. I was getting to know their 
unique ways of doing and being. Therefore, I was able to appropriately guide and support their professional learning and development according to their individual needs.

Another good example of my successful provision of individualized support is when Teacher F seemed overwhelmed all the time and cannot seem to keep up with her workload. This was out of the ordinary, as I knew she normally manages her time well. I met with her one afternoon and asked quite simply - "how are you?". Teacher F let out a big sigh and "she said she has a lot of things going on and cannot seem to keep up. She knows she's not achieving as much as she'd like but she's working on it. She said that she's recently figured out a system that helps her tick things off as she goes. She cannot plan too ahead of time as that just doesn't work for her. However she knows what's coming up and what needs doing and she goes through each according to priority" (Entry dated 28.3.16). I asked her what I could do to help and "she said maybe catching up on Mondays will be helpful as it'll set her up well for the week, and spread all her 'to-do's' throughout the week.." (Entry dated 28.3.16) I agreed with this plan and for the next two weeks, I specifically asked every Monday 'what's on top' for her that week. It seemed to have worked, "as she seems more 'in control' lately. Maybe talking through someone is helpful enough..." (Entry dated 11.4.16).

Prior to these conversations, I have already developed a good working relationship with Teacher F. I knew her well enough to believe that her lack of performance was out of the ordinary. I also knew from experience that she generally came up with 
solutions to issues or challenges herself. With this existing knowledge, other than asking in the beginning how things were going, I allowed Teacher $F$ to lead the conversation, and I just listened. By taking the time to just listen, I allowed her the time and space to unpack her thoughts and come up with a solution herself, which was for me to be her 'sounding board' to help her plan and prepare for her week. Individualizing the way I supported Teacher F I believe contributed to her success.

\section{Better Time Management}

This particular entry was noteworthy as it indicated a significant shift in my thinking as a Professional Leader about time management. I had been feeling stressed and inefficient for a number of days. I felt I was not achieving any of my goals and responsibilities. This prompted a journal reflection one evening after a particularly unproductive day.

21.3.15 - "I felt completely unproductive today! What did I even do?! ....talked all day to at least 4 teachers during their breaks about a variety of things which, to be honest, are completely irrelevant to (centre) work, like travel plans in a few month's time....Although I did enjoy these spontaneous conversations, it took at least $10-15$ minutes of my time when I should be concentrating on (admin work)...I also needed to plan and prepare for the next team meeting but I didn't have enough time to do that..."

I decided to add up these 15 minutes chat with every teacher who came in for her tea break. I learned that these seemingly short chats added up to two hours in total. 
“...2 hours for when teachers go on morning tea break, another 2 hours for when they go on their afternoon tea $=4$ hours talking time! My day consists of 4 hours 'on the floor' and 4 hours admin. Without realizing it, my 4 hours admin has been taken over by 4 hours talking time! No wonder I feel exhausted and unproductive! I need to better manage my time!" (Entry dated 21.3.15)

This was a significant eye-opener for me. Up until when I wrote this entry, I have been feeling stressed out as I never seem to be achieving any of my daily goals. It was not until I wrote this particular entry down when it dawned on me how much time the seemingly short catch-ups are consuming. I realized that I was not effectively utilizing my administration time. I also realized that perhaps it is due to this poor time management that I was unable to plan for and prepare efficiently for team meetings. This ultimately would lead to unpreparedness for leading team meetings, an observation picked up by our centre owner when she conducted observations of my leadership practices as part of this study's data collection.

The following entry reflects actions I have taken to improve my time management skills. This was also a follow on from the same entry (dated 19.4.16) about regularly reminding the team of the centre vision.

19.4.16 - "I have been scheduling 'Head Teacher Planning Time' at least 4 hours every week to ensure I spend quality time looking at 'big picture' planning, like reflecting on where the programme is currently, and how I can continue to support and inspire the team to challenge themselves further and 
facilitate children's investigations to a deeper level...l have also been purposely spending a few hours ahead of team meeting evenings to intentionally prepare and plan for teachers' learning... I clarify my objective for teachers' learning, and purposefully weaving in the vision...this includes considering how this meeting would connect with the previous meeting, and how it can progress onto the next meeting... I have been more thoughtful with my questioning, that ultimately encourages teachers' thinking about the centre vision.

Since implementing this leadership strategy of setting aside time especially for 'Head Teacher planning', I have found that I was able to keep on top of all of my administrative tasks better, whilst at the same time, still managed to be available for the team to approach should they need a catch up with me. I have successfully balanced both my management and educational leadership responsibilities.

\section{Summary}

Findings from this study highlighted five main attributes participants believed are important for a Professional Leader to have. Firstly, a Professional Leader must communicate clearly and frequently with the team. Regular 'catch ups' were deeply valued and appreciated as it showed that the Professional Leader cared for each member of the team and encouraged the development of relationships and trust amongst the team. 
Secondly, a Professional Leader must be an active listener. The act of listening involved the Professional Leader's receptiveness to others' perspectives without making any presumptions, especially if there is conflict involved.

Thirdly, a Professional Leader must be available and be approachable, especially in times of team's needs. Further analysis of collated data showed that this particular attribute was a preceding factor to the two attributes mentioned earlier. A Professional Leader must make time to be available for regular 'catch ups', while at the same time, allow to be approached by team members spontaneously when the need arises.

Fourthly, a Professional Leader must be accountable for his/her actions. He/She must be accountable with her time. Following through one's word is something the team highly valued and is a strong precursor for further development of their trust in the Professional Leader.

And lastly, a Professional Leader must be consistent with his/her expectations. Not only is following through one's word important, but also demonstrating that a Professional Leader's actions and expectations of team members are consistent regardless of who or what is involved effectively influences the level of trust the team would have in the Professional Leader.

Findings showed that demonstration of all five attributes by a Professional Leader promote the team's development of trust in the leader. Furthermore, each attribute 
compliments and builds on the next, together strengthening the relational trust between a Professional Leader and the team. 


\section{Chapter Five}

\section{Discussion}

This study aimed to explore leadership conceptual understandings and practices that help strengthen the relational trust between a Professional Leader and the team. To begin with, this chapter briefly revisits the definition of relational trust. It then presents a discussion of the key findings outlined in the previous chapter with reference to relevant literature. The discussion is structured following the diagram introduced in the previous chapter. It discusses how, in order to strengthen the relational trust between a Professional Leader and the team, a Professional Leader must communicate clearly and actively listen; be available and approachable; be accountable; and maintain consistency.

\section{Relational Trust}

Participants in this study defined relational trust as trusting each other to complete their respective roles and responsibilities and "get things done". This definition is consistent with Bryk and Schneider's (2003) research findings, which explained that relational trust is founded on both beliefs and explicit expectations regarding each other's obligations.

Trust appears to diminish when individuals perceive that others are not behaving in ways that are recognized as consistent with their expectations about the other's role obligations. For example, participants in this study identified being a "good listener" as a trait they believe a Professional Leader should have. One participant added that 
should a Professional Leader not fulfill this particular expectation, it deters team members from further sharing any more thoughts or feelings with the Professional Leader. This is likely to have implications for a team member's well being as they may feel unsupported or misunderstood. This may also slow down or even hinder any possibility for their trust in the leader to mature to the next level.

Furthermore, the fulfillment of obligations on which relational trust rests entails on not only 'doing the right thing', but for what are perceived to be the 'right reasons' (Bryk \& Schneider, 2002, p.21). For instance, one participant noted in the second survey that though I do well empathetically managing various circumstances and diverse life challenges amongst the team, it is ultimately my role and responsibility as the Head Teacher to make the final, sometimes hard, decisions, that are beneficial, not just for one or two teachers, but for the team as a whole.

Relational trust is not a concept with a prescribed set of steps. Rather, it entails a distinct set of interpersonal qualities that are conveyed through actions. As previously mentioned, Bryk and Schneider (2002) talked about four leadership qualities that engender relational trust - respect, personal regard for others, role competence, and personal integrity.

Participants in this study explicitly mentioned the word 'respect' in both surveys as one of the traits professional leaders should have, which is consistent with one of the four qualities Bryk and Schneider (2002) discussed. However, a thematic analysis of all data sources highlighted other qualities. 


\section{Strengthening Relational Trust between a Professional Leader and the Team}

Findings from this study drew attention to five main attributes participants believed to be important for a Professional Leader to have in order to gain the team's trust. These are: communication, active listening, availability/approachability, accountability, and consistency.

The following diagram (Figure 5.1) describes how the identified attributes, with reference to Bryk and Schneider's work (2003), help strengthen the relational trust between a Professional Leader and the team.

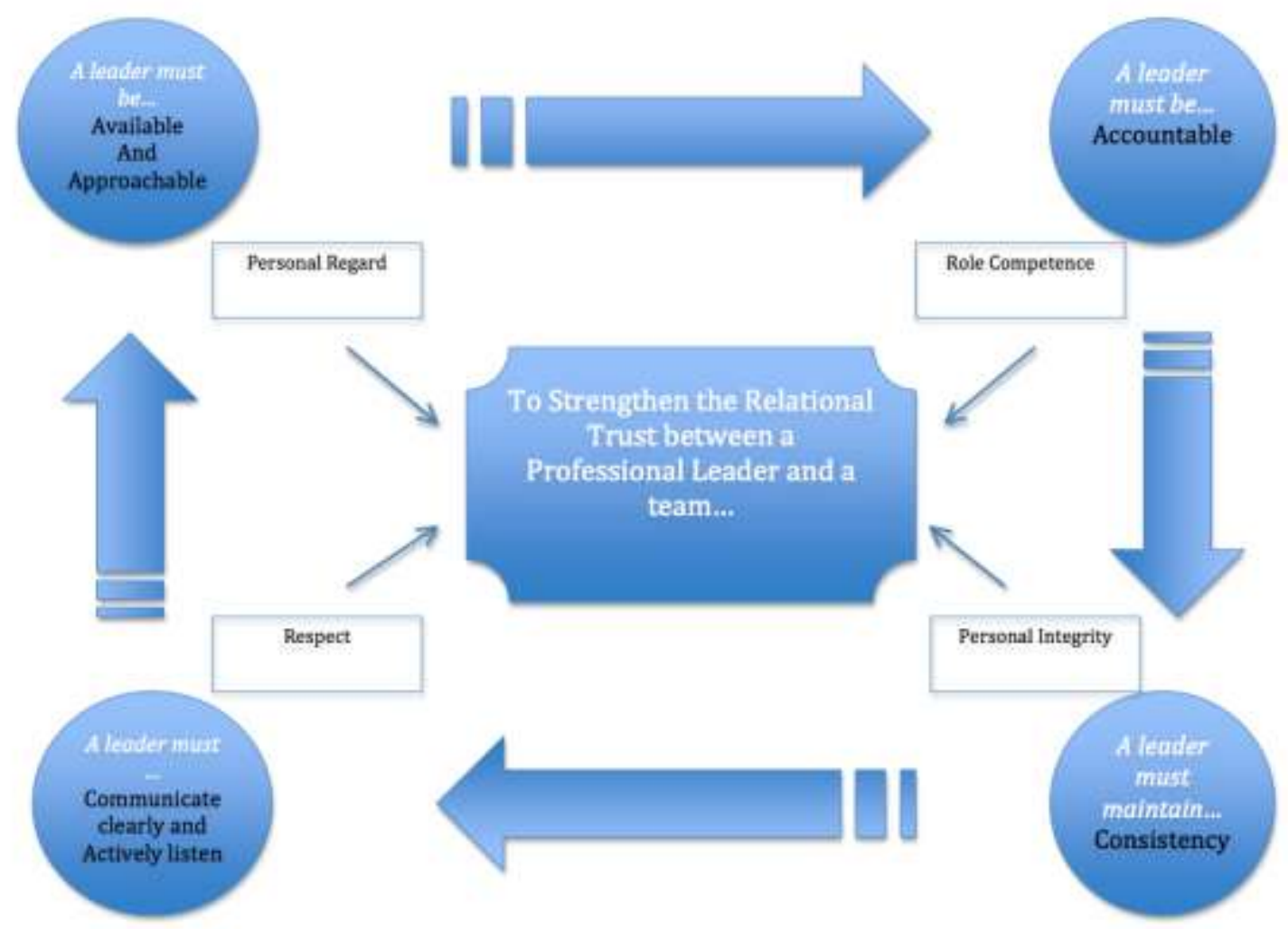

Figure 5.1 
To strengthen the relational trust between a Professional Leader and a team, a leader must communicate clearly with and actively listen to team members' thoughts and ideas. In doing so, a leader demonstrates respect as described by Bryk and Schneider (2003). To allow for this dialogue to occur, a leader must allow time to be available for team members when their need for a conversation arises, thus demonstrating a Professional Leader's personal regard for others' well being. With a variety of achievements and challenges members of the team may want to share, a Professional Leader must then be accountable with one's time. A leader must learn to prioritize - "What's important?", "Will this benefit the whole team, the children's learning?" I believe being accountable is a skill that is learned as a Professional Leader becomes more competent in his/her role. Finally, a leader must maintain consistency. A leader must communicate consistent expectations across the team; whilst at the same time ensure that each teacher is given an equitable opportunity to succeed in their role. Being consistent demonstrates a Professional Leader's personal integrity as described by Bryk and Schneider (2003). These five attributes rotate in a clockwise direction, each contributing to the strengthening of relational trust between a Professional Leader and the team.

Each attribute will now be considered in relation to findings and relevant literature. I will also discuss changes in my practice and leadership strategies I have used as a response to data collected since the first survey. 'Communication' will be addressed first. 


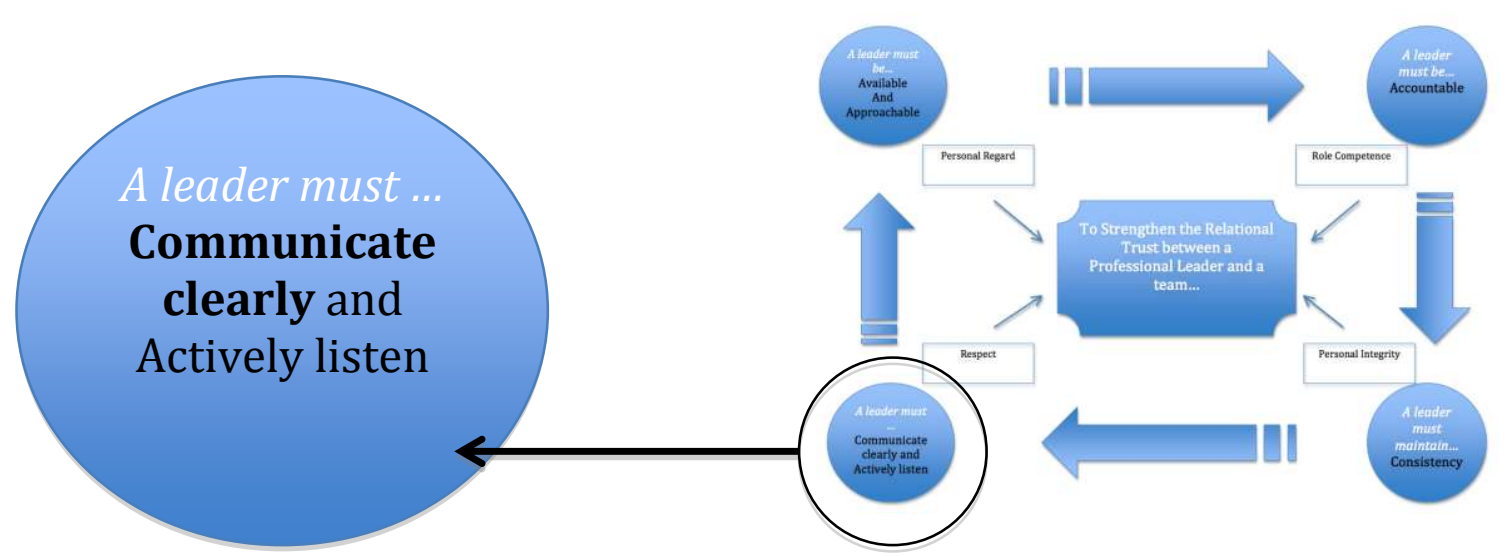

Figure 5.2

This study reveals that successful leadership in early childhood is a matter of communication more than anything else. In a field where most of the work is centered on relationships with groups of people - children, their families, fellow staff members, and wider community - the ability to communicate clearly is absolutely essential. Effective leaders must be skilled in communicating vital information clearly and succinctly to different members of the team, particularly in articulating a shared vision in providing the direction for an early learning service (Rodd, 2013). Three facets of communication were identified in this study - communicating the vision; daily team communication; and open-to-learning conversations. Communication the centre vision will be discussed first.

\section{Communicating the vision}

As discussed earlier, a vision is referred to as the 'big picture', the why we do the things we do, and it is the leader's role to ensure its realization (Hipp \& Huffman, 
2010). However, with a team of nine teachers, I personally found it challenging to ensure that each member of the team receive the same messages in a timely manner. In my first few months as Head Teacher, I used our fortnightly, two-hours team meeting evenings to pass on information the whole team needed to know, may it be about any updates about a child/family, or any housekeeping-type discussions such as reminders to empty the nappy bin at mid day. However, I felt too much time was spent focusing on the technical aspects of ensuring the Centre runs smoothly. I think it may have impeded us from engaging in any learning conversations that would have moved the team towards a deeper understanding and better implementation of the Centre philosophy.

\section{Change in Practice}

A leadership strategy that was implemented as a result of this study, as well as in response to one participant's specific suggestion that I as the Centre's Professional Leader share more of what my long-term vision is with the team, is clearly and constantly communicating the Centre vision, and emphasizing team professional learning and development towards the achievement of that vision, during team meetings.

Communicating the Centre vision involved intentionally weaving in the word 'vision' into the meetings, as documented in a journal entry in the findings chapter. For example, before asking the team to implement new or improve current practices, I would explain that "it is my vision that collectively as a team we would be able to...(goal), hence I believe having a team understanding of...(theory/idea/concept) 
will help us get there". This study reveals that by intentionally reminding and communicating with the team of the vision frequently, the team could move their focus from the everyday details towards thinking more about and connecting more with the 'bigger picture'. In time, team meetings became more strategic, with each meeting purposefully building on from the last one. Discussions about the Centre curriculum and programme grew deeper and more reflective, and more profound understanding of each other's teaching philosophy and practices developed. This strategy promoted a consistent and collective professional growth of the team.

With team meetings more focused on 'living' the vision, discussions about the technical, day-to-day aspects of a Centre's day were reallocated through another means of communication, which will be discussed next.

\section{Daily Team Communication}

This study reveals that participants seemed to value the importance of clear communication about the daily running of the centre. One participant specifically explained that the consistency and timeliness of messages being passed on to the team influences how a teacher's trust in the Professional Leader would develop. A literature review of management skills within a business sector provided many strategies a leader may use to best utilize his/her time, which may be applicable within an ECE setting. However, I was not able to obtain one that was specifically for ECE. 


\section{Change in Practice}

Since shifting the focus of team meetings agenda on teachers' professional learning and development, another leadership strategy that was implemented as a result of this study is the use of different communication means for those still important housekeeping-type discussions. An existing method even before this study began was by writing brief notes and reminders in the staff diary. The challenge with this method however, was the limited amount of space. It was rather one-sided too. It only allowed the writer to communicate, but restricted the reader from responding due to its limited space.

Therefore, I instigated the use of StoryPark ${ }^{T M}$ - an online tool our Centre uses to document and share children's learning experiences with families - as another communication method with the team. It has a 'conversation section' where I can send messages to members of the team, similar to e-mail. It allowed for more detailed, reciprocal conversations that a diary could not provide.

Why not e-mails? The challenge with e-mails I found was that there were some teachers who do not check their e-mails frequently enough, therefore messages sent through this method may be missed. Generally, the team logs in to Story Park ${ }^{T M}$ at least twice a week during their non-contact time to post updates for families about their child's day/s at the Centre, e.g. to write learning stories. Thus writing on StoryPark ${ }^{T M}$ ensures that the team receives important messages posted by myself, or others, within the week, if not immediately. One participant noted this method of communication guaranteed that the whole team would receive the same message in 
a timely manner. This study shows that utilizing a tool or method already being used, instead of adding another task to teachers' existing non-contact duties, were greatly appreciated by participants.

The following section will now discuss the significance of open-to-learning conversations as a key leadership skill.

\section{Open to Learning Conversations}

Findings revealed that engaging in open-to-learning conversations (OLC) is a leadership skill I needed and have been working on as a result of this study. Participants noted that although it seems I communicate well, I might not be actively seeking other's perspectives.

OLC (Robinson, Hohepa \& Lloyd, 2009) is a strategy leaders can use, especially in situations where difficult issues need to be addressed whilst developing and maintaining trusting relationships with the team. A literature review of OLCs will yield sources that discuss in steps how to effectively conduct OLCs within educational settings.

At the heart of OLCs is the value of openness to learning with and from others about the information, beliefs and reasoning that each person brings to the conversation. Trust is built through these conversations that are deeply respectful of people, and simultaneously tough on problems that needs to be dealt with. 
Integral to OLCs are three values - respect for self and others, valid information, and internal commitment to decisions (Robinson et al., 2009). We respect ourselves and others when we say what we think and give equal consideration to our own and others' perspectives. We respect others by seeking their views, actively listening and being curious rather than judgmental about why they think differently from us. Giving them choices and treating them as partners in the conversation also demonstrate respect for others.

The value of valid information is about being open to checking and testing our assumptions about each other, about the problem or task, and about what to do. This is a particularly important value because decisions made by professional leaders have significant implications to the team's work lives. Therefore, leaders have an ethical obligation to actively seek validity to test and improve the quality of one's own and others' thinking and understanding.

With valid information and respectful processes in which people feel heard and have genuine opportunities to exercise influence, the team is more likely to feel a sense of ownership and commitment to decisions made as a result of these conversations. Their internal sense of motivation will be guided by their own convictions about the importance of their work to children's holistic development.

OLCs are not only used in challenging circumstances. Encompassing the three values that make up an OLC, respectfully seeking validity in one's understanding of what the 
other person is saying is very much relevant in all sorts of conversations. Therefore, the skill to engage effectively in an OLC is highly important for a professional leader.

\section{Change in Practice}

Espousing these values in everyday conversations can be difficult to consistently live up to, as I have noted in one of my personal journal entries. It was habitually easy to give in to my own assumptions and create conclusions without completely gathering all the facts, or the point of views of those involved.

Findings revealed that communication alone is an insufficient skill for Professional Leaders to have. Whilst conveying one's thoughts and ideas are vital, it is equally important that Professional Leaders are able to actively listen too. The attribute of 'active listening' will be discussed next.

\section{A leader must actively listen}
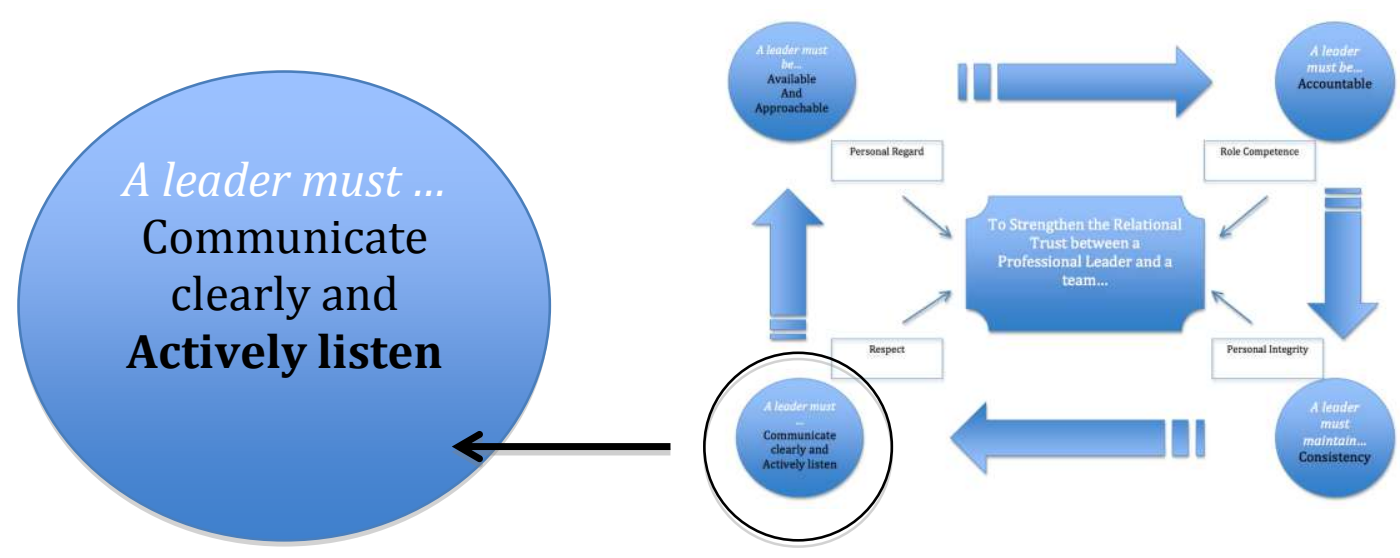

Figure 5.3 
Findings revealed that while I seemed to communicate well, listening was a skill I needed to work on. Therefore, it is important to note that this is a skill I thoughtfully considered and reflected on, and is evident through the section 'personal reflections'.

While communicating clearly is an important leadership skill to have, it is equally as important for a leader to listen to what was being said. According to Goleman (1996), listening to and focusing on the feelings of what is being said is fundamental for the receiver to be fully receptive to the message the speaker is trying to convey. An effective leader therefore must really exert the effort to understand and utilize all information - both that are verbally said, and the underlying feelings conveyed by the speaker - to completely comprehend the meaning of the message as the speaker had intended. This type of listening is described as 'active listening'.

Active listening is one of the most important, and challenging leadership skills that all leaders need to strengthen (Kouzes \& Posner, 2007). Through active listening, leaders build trust and respect because they're conveying to their colleague that what they are saying is worth listening to. To listen without interrupting or sharing one's own stories or giving advice sometimes unasked is something that leaders often find difficult (Robertson, 2016).

Robertson (2016, p. 118) identified a list of listening guidelines to be an effective active listener. It is advised that leaders should: give the speaker your full attention; encourage that person to keep talking; not break into the conversation by sharing 
your own experiences - 'war stories'; not give advice; take careful note of what is said, in writing if necessary, and listen closely for what is not said and for what is important to the speaker.

\section{Personal Reflection}

Out of these guidelines, I have found restricting myself from sharing my own experiences as the most difficult to do. I believe in my nearly fifteen years as an early childhood education teacher, I have learned quite a lot and developed a number of practical skills. I believe the experiences I have had and lessons I have learned over the years gave me the competence and confidence to be a professional leader. I think this is why when a team member comes to me with a challenge, and if it is something I have previously experienced, or have knowledge about, I often find myself sharing my own stories as a way of empathizing with the other person. It was a way of saying, "I know and understand how you feel, what you are going through. I have been there. I have had the same experience".

How leaders respond affects the quality of the interaction (Rodd, 2013). Carl Rogers (1961) identified five response styles commonly used in verbal communication in people-centred organisations. These are: Advising and analyzing. The purpose of this response is to give advice - 'What you should do now if I were you...'; Interpreting and analyzing. The purpose of this response is to interpret information given - 'The real issues here is...'; Supporting and placating. The purpose of this response is to diminish emotions - 'Don't worry, it'll be OK...'; Questioning and probing. The purpose of this response is to gain more information, but may turn into interrogation 
- 'Anything else happened? Is everything alright...?'; Understanding or reflecting. The purpose of this response is to focus on the underlying feelings as well as the content, often in a short paraphrase that indicates their understanding of the message - 'You seem pleased about his progression...'

\section{Personal Reflection}

The response of "I know how you feel..." seems to indicate that of a 'supporting and placating' type. Though an expression of sympathy may justify such a response, upon reflection, I may have unknowingly been brushing my colleague's emotions away. "I know how you feel..." seems to indicate that I already knew what the other person was feeling or thinking, hence there was no need for me to listen to anything else she had to say. I was not actively listening - to her words, nor to any underlying messages possibly conveyed non-verbally. I did not acknowledge her feelings. Instead of engaging in an open-to-learning conversation (OLC), and actively listening to my colleague, the conversation became about me and my experience - what / did when I experienced what my colleague was now experiencing, and what I learned in my experience. As I further contemplated this seemingly innocent "I know how you feel..." this response also was an 'advising and analyzing' type, as the sharing of my own stories may have been my subtle way of giving advice -my colleague could do what I did now that she's experiencing what I have experienced.

All five types of responses, while appropriate at times, can have detrimental effects to communication if they are adopted insensitively (Siraj-Blatchford \& Hallet, 2014). It is important for leaders to "be aware of the advantages and limitations of the 
different response types, and use their experience and expertise to determine which would be the most productive for meeting others' needs in the circumstances" (Rodd, 2013, p.75).

It is equally important to identify barriers to the communication process - such as an inappropriate environment where there is too many background noises, or differences in communication styles - as it is through communication that information is shared, trust is established and relationships developed and maintained. Leaders need to seek solutions to these barriers so they may give their full attention to the speaker and actively listen and engage in an effective OLC (SirajBlatchford \& Hallet, 2014).

\section{Change in Practice}

This study reveals that an immediate barrier to an effective OLC would be the busy environment ECE learning services naturally endures. A leadership strategy that was developed based on this study's findings was to ensure sufficient time and opportunity is allowed for each teacher to communicate with the Professional Leader, in a space away from any communication barriers. I have learned ways I can be available, so the team can approach me if and when they need to, one of which is through regular 'catch ups' with individual teachers. The next attribute, 'availability/approachability' will be discussed in the following section. 


\section{A leader must be available and approachable}

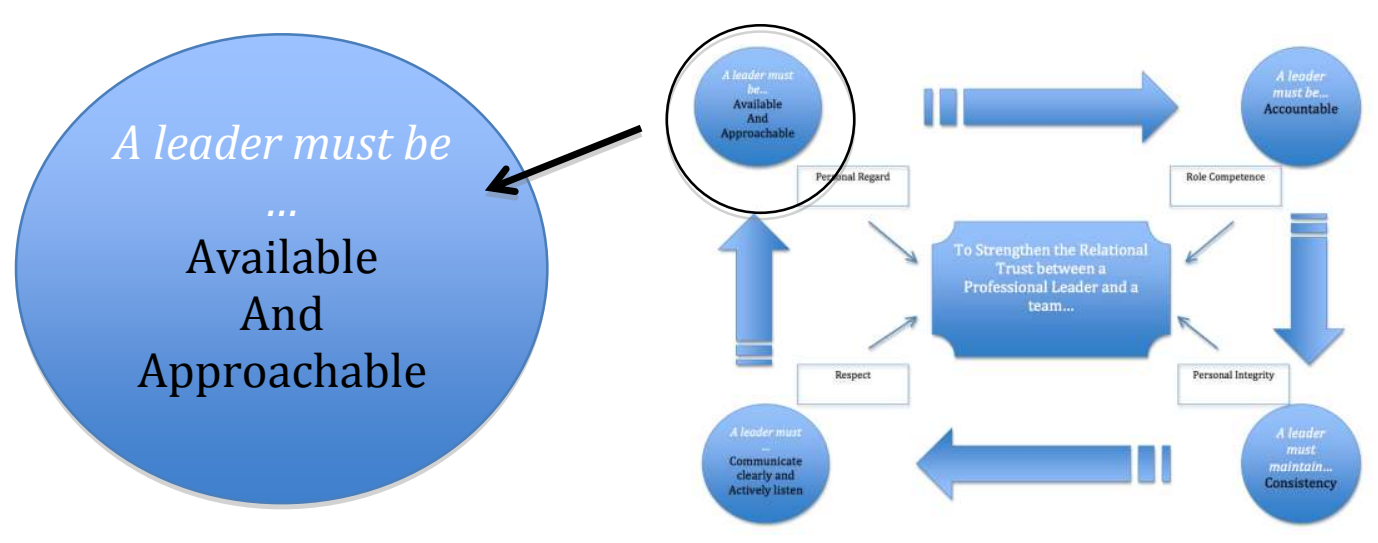

Figure 5.4

Participants in this study conveyed how much they appreciated 'catch ups', as these allowed them the opportunity to communicate with me anything that was important for them at the time. In particular, one participant explained that initiating these catch ups showed that I cared for their well-being, which ultimately increased their trust in me as the Professional Leader.

Adults bring an intricate web of skills, knowledge, personality, experiences, values and beliefs into the workplace. Events they've encountered throughout their life influences their self-image and how they respond to children, as well as their colleagues. It is then vitally important that leaders take time to discover who each member of the team is - what they already know, what their interests are, as well as their goals and aspirations are (Carter \& Curtis, 2010). It is for this reason why regular 'catch ups' with each teacher were initiated as a key leadership strategy. 


\section{Change in Practice}

A catch up may be a quick check or query from a Professional Leader about how their day was going during their lunch break, or it could be more intentional meetings where a mixture of personal and work conversations are discussed. Through these catch ups, I learned about their goals and aspirations, as well as their challenges and frustrations. I learned which coaching and mentoring strategies work with specific teachers. Regular catch ups, as findings shows, allow a Professional Leader to become closely familiar with a team member's natural way of being, that it would be easier to identify any subtle change in behaviour. Additionally, Professional Leaders are also more able to provide personalized support that compliments a teacher's particular character and individual strengths and capabilities.

Catching up on a regular basis with nine teachers eventually became challenging, as I juggled between 'being there' for the team, whilst ensuring sufficient time is allotted for Ministry-required administrative tasks, as well as strategic planning. I was constantly getting interrupted and distracted from my tasks on hand due to many spontaneous requests or need to engage in conversation with team members. I realized after documenting in my personal journal a particularly unproductive day that I have been spending all of my 'administrative time' simply catching up with the team. As a result, I was failing to meet and falling behind my administrative responsibilities. I realized I became 'too available'. I was not using my time efficiently enough to ensure I am achieving all of my responsibilities in a timely manner. I needed to become better accountable with my time. 'Accountability' as a key attribute will be discussed in the following section. 


\section{A leader must be accountable}

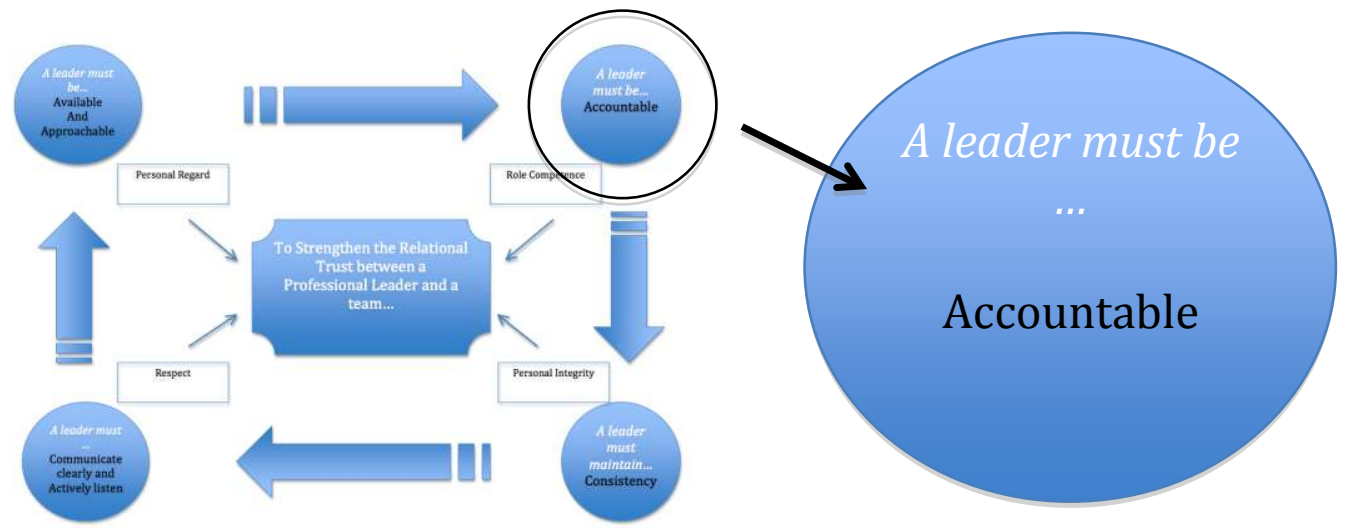

Figure 5.5

This study reveals how important it is for a Professional Leader to be accountable with his/her time. Leadership in ECE is a multifaceted phenomenon where leaders are required to constantly balance their time between administrative tasks and educational leadership. With "a multiplicity of demands (and) many pressing responsibilities...in a context of potentially conflicting needs from a range of parties" (Rodd, 2013, p.79), it is essential that leaders respond and work in ways that meet their professional needs. It is important that leaders are effectively accountable with how they utilize their time to ensure, not only both responsibilities are met and adhered to, but also their well being looked after and taken cared of.

The ability to effectively prioritize tasks and responsibilities is paramount. Effective time management, which involves "clarifying and prioritizing goals in one's personal and professional life, and establishing action plans and timeframes for the tasks to be undertaken in order to achieve these goals" (Rodd, 2013, p.91) is crucial. "The key is not to prioritize what's on your schedule, but to schedule your priorities" (Covey, 
1989, p.161). A leadership strategy was devised as a result, termed as "Head Teacher Planning Time" (HTPT).

\section{Change in Practice}

HTPT is an intentional planning time that occurs at least once a week where I prioritize all my Head Teacher tasks and responsibilities. It normally starts by looking at the centre's annual management plan at the end of the month to check for any legislative requirements that need immediate actions within the following month, e.g. policy reviews. I also check at the end of the month whether I have achieved all actions required; if not, tasks that were not dealt with, depending on how important it is, get carried over to the following month's priorities. I apply the following guidelines (Rodd, 2013, p.91) when deciding a task's level of priority: Urgent and Important - do it now; important but not urgent - can do it later today or tomorrow; this week - attend to it within a week; this month - record its deadline to prompt attention; revisit its level of priority closer to the deadline; break - non-urgent tasks are done when all important tasks are completed.

When deciding whether a task is urgent and important, it is valuable to consider its relevance based on legislative requirements, and the Centre vision. For example, if I spend time on this task, will it help achieve the centre vision? If yes, prioritize it. If not, decide if it is worth following up on.

In saying this, HTPT can also be utilized to becoming more strategic - one of the most common goals leader have (Garvey-Berger, 2012). Other than dutifully completing all 
necessary administrative tasks, a Professional Leader must focus on the Centre's vision (Hipp \& Huffman, 2010). Time is spent reflecting on the educational programme, and plan ways on how the team can improve its provision in order to further deepen possibilities for children's learning and exploration. In particular, HTPT can be used to prepare for an upcoming team meeting, where a Professional Leader can intentionally plan the team's professional learning objectives in relation to the Centre vision - how can I highlight the vision in this team meeting? - and prepare teaching methods, e.g. workshops that would help with the achievement of the learning objectives, and consequently, the vision.

Since implementing this strategy, this study reveals a more balanced achievement of both management and leadership responsibilities that are required of a Professional Leader.

\section{A leader must maintain consistency}

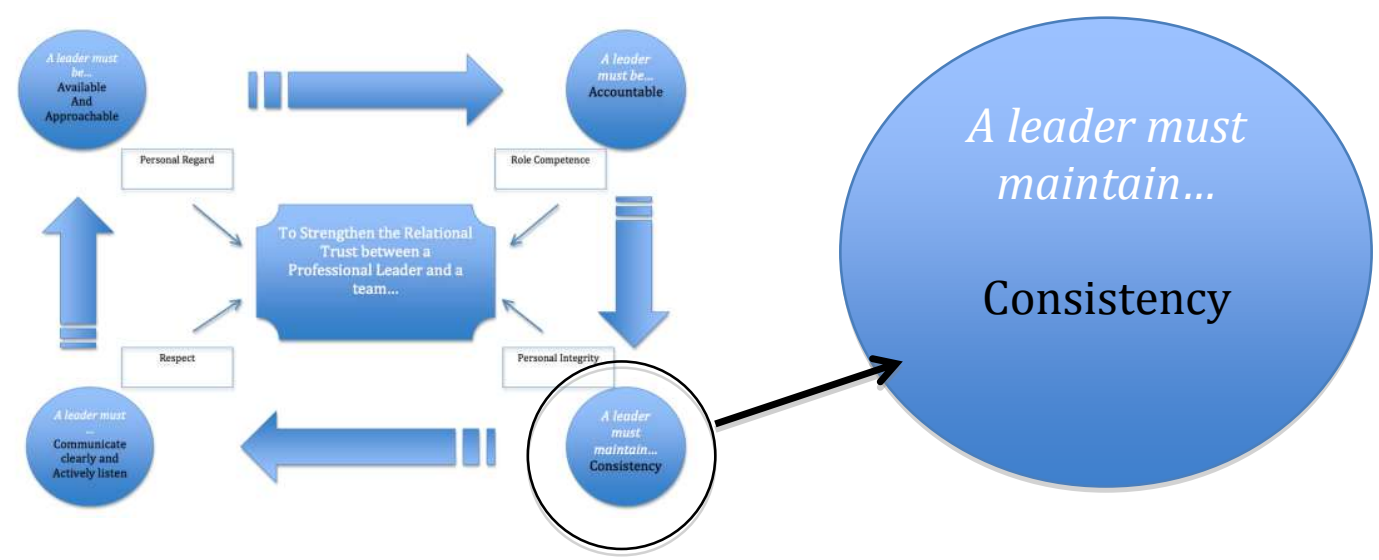

Figure 5.6

Even distribution of responsibilities amongst the team is a reason why consistency of expectations must be maintained as participants in this study disclosed. However, it 
is also important to acknowledge the individual experiences and capabilities each teacher brings to the team. Evans (2000) affirms that if leaders are consistent, true to their word, and can be counted on, then they can be trusted in the organization. Recalling Bryk and Schneider's research (2002), integrity, as the fourth determinant of relational trust, relies on whether or not there is consistency between what a Professional Leader says and does. It is for this reason why it is important for a leader to maintain consistency within the team. Consistency is key to developing the relational trust between a Professional Leader and the team (Bryk \& Schneider, 2002).

\section{Change in Practice}

Utilizing the leadership strategies discussed so far - OLCs, regular catch-ups, active listening, HTPT - a Professional Leader will be able to personalize the support and guidance given to each member of the team. In doing so, every teacher will have an equitable opportunity to succeed in their role.

Following on from the discussion about communication earlier, Rodd (2013) highlighted the importance of sending "accurate and unambiguous messages" (p.70) given that it is a Professional Leader's responsibility to disseminate huge amounts of information at different levels within an early childhood service. A participant in this study emphasized the need for a Professional Leader to understand the different ways each member of the team communicate. With this knowledge of each teacher, clear and accurate messages can be consistently constructed (Rodd, 2013) through engagement in OLCs. Consequently, this then leads back to the first attribute 
identified in the diagram - communication - and the cycle repeats. Each attribute builds on each other, contributing to the overall strengthening of relational trust between a Professional Leader and the team.

\section{Summary}

This study identified five attributes that were important for a Professional Leader to have in order to strengthen their relational trust with the team as seen in figure 5.1. Firstly, a Professional Leader must have the ability to communicate clearly and to actively listen. Clear communication involves an intentional focus on the centre vision at all times to ensure the team is collectively working towards its realization. This also involves purposefully seeking different methods of communication so that times when the team gets together (such as in team meetings) is utilized more effectively and be more focused on the team's professional learning and development. Active listening involves listening to and focusing on the underlying messages the speaker is saying. This means a Professional Leader must constantly seek validity in their understanding of the message, which can be practiced by engaging in an OLC

Secondly, a Professional Leader must be available and approachable. It is important that Professional Leader take time to discover who each member of the team is. A Professional Leader must therefore allow time to be available for the team to approach when their need to communicate and be listened to arises. This study reveals the value of regular catch-ups with each team member as an effective way for a Professional Leader to become familiar with their individual personalities, 
aspirations and goals, as well as their strengths and capabilities. In doing so, a Professional Leader is able to provide a more personalized support and guidance that truly benefit the individual teacher's professional learning and development.

Thirdly, a Professional Leader must be accountable with his/her time. A Professional Leader must competently carry out all his/her responsibilities. As a result of this study, a leadership strategy termed as "Head Teacher Planning Time" (HTPT) was created. This is when a Professional Leader intentionally allocates time in the week to prioritize administrative tasks, as well as to focus on the Centre vision as part of strategic planning. This study reveals that implementing this strategy results to a Professional Leader's balanced achievement of both management and leadership responsibilities.

Finally, a Professional Leader must maintain consistency. The ability to be consistent reflects on a Professional Leader's sense of integrity, and has a direct influence on whether or not the team trusts him/her. This study reveals that consistency is the final attribute that connects all attributes together. This is the point in the diagram where it rotates back to the first attribute. A Professional Leader must communicate consistent messages. A Professional Leader must consistently allow time for regular catch-ups to occur. A Professional Leader must be consistent with his/her allotted HTPT to ensure accountability of responsibilities. Consistency is key to strengthening the relational trust between a Professional Leader and the team. 
The following, and final chapter will now discuss this study's limitations as well as recommendations for policy and practice and suggestions for further research. 


\section{Chapter Six}

\section{Conclusion}

This chapter concludes this study's findings as well as examines its research limitations. It discusses recommendations for policy and practice and suggestions for further research.

\section{Summary of Findings}

This section addresses the research question:

What leadership conceptual understandings and practices will help strengthen the relational trust between a Professional Leader, and the team?

Findings from this study revealed five attributes that were important for a Professional Leader to have in order to strengthen their relational trust with the team. Firstly, a Professional Leader must communicate clearly. Secondly, a Professional Leader must actively listen. Thirdly, a Professional Leader must be available and approachable. Fourthly, a Professional Leader must be accountable. And finally, a Professional Leader must maintain consistency.

\section{Conclusions}

As previously discussed, there is currently no requirement that an ECE teacher must undergo any leadership training before taking on a leadership role (Aitken, 2013). I personally find this concerning. Leadership is a complex responsibility (Fasoli et al, 2007). I came into my current leadership position armed with some knowledge and 
leadership experience. I also made the conscious choice of studying further to learn more about leadership by undertaking this research study. It was 'hands on' experience, combined with comprehensive literature review and research, and professional learning conversations with colleagues both in and out of the centre I work in, where I learned and developed the skills and attributes discussed in this study.

In spite of this, I was still unprepared for the realization of how multifaceted leadership truly is. I was still unprepared for the challenges being in a position of leadership bring, both mentally and emotionally, as I have mentioned in chapter three. If, in spite of my existing knowledge and learning gained from undertaking this research study, I still felt unprepared, how well would a less experienced teacher taking on a leadership position manage without any leadership training?

As discussed in chapter two, there is a lack of leadership development programmes within and specific to the ECE sector. Thornton et al. identified this issue back in 2009, and nearly eight years later, there has been minimal increase in specific leadership training in ECE. With this as the existing New Zealand ECE context, how can current leaders, or those aspiring to be one, be effectively prepared for the "formal, complex leadership and administrative roles and responsibilities required for leading contemporary inclusive, integrated, multi-disciplinary, multi-agency early childhood services" (Rodd, 2013, p.39)? Recommendations will be made at the end of this chapter. This study's limitations will be discussed next. 


\section{Limitations}

This study acknowledges its limitations, all of which I have anticipated right from its ethics application. First of all, it is a small-scale research, with just nine participants, with whom I am in a relationship of power to (Mutch, 2013); therefore its validity could be questioned (Punch, 2009). Secondly, although both online surveys were anonymous, there was the risk of participants not providing full disclosure during their professional conversations, again, due to myself as being in a position of power. Thirdly, as discussed in chapter three, conducting this research in my place of work brought about personal challenges. Because data gathered were not completely anonymous, though it was strictly confidential, I found the data analysis process emotionally overwhelming. This therefore required a longer period of time than anticipated, to fairly analyze all sets of data.

However, while these have been noted as this study's limitations, these same factors also provided its strengths. Firstly, having the existing relationships with the participants allowed me to understand their thoughts, and suggestions a lot better. I feel our relationship has grown deeper as a result of this study - it was focused on strengthening our relational trust after all. Secondly, conducting this research in my place of work allowed me to combine the growing theoretical knowledge I was gaining from this study straight into my practice, which made the learning process a lot more meaningful for me. Thirdly, even though the process of data analysis was overwhelming, I believe it provided me with great insight into the participants' minds, which otherwise I would not have known if not for this research purpose. This process I believe have made me a better Professional Leader. 


\section{Recommendations}

As a result of this study, I propose the following recommendations:

To Centre Owners/Managers:

1. Before promoting a teacher to any leadership role, ensure that you critically appraise their performance and use this information to decide whether he/she is ready for the complexities leadership will bring. This means only giving them the leadership responsibilities if and when you are certain he/she can effectively and confidently manage the mental and emotional challenges leadership brings.

2. Provide centre leaders sufficient time and adequate support. Provide them time, e.g. extra non-contact time, so they may effectively and successfully meet both their leadership and administrative responsibilities. Be available for them to approach, for example, to run an idea past you, or simply to be a person they can confide in. Leadership often is thought of as an isolated role (Christie, 2016). Leaders need someone to share with and talk to about both their challenges and successes. Support their growth by actively providing them opportunities to further their leadership capabilities and understanding, e.g. through leadership development programmes.

To the Ministry of Education and the Education Council:

1. Make undertaking leadership training a requirement before any teacher progresses into a Professional Leader's role, i.e. the person responsible for the overall running of a centre. This may be through a tertiary institution as a formal qualification, or through small-scale professional development 
providers. In doing so, it ensures that teachers are well prepared for and well aware of the intricacies leadership brings. This also ensures that only those who are mentally and emotionally ready for the responsibilities and challenges are positioned as Professional Leaders. It will be a teacher's conscious, well considered choice to make, instead of being a role handed to him/her simply because he/she is a qualified teacher, as Thornton et al discovered in their research back in 2009. This proposed requirement might need a change in government policies such as Education (Early Childhood Services) Regulations 2008.

2. There needs to be more easily accessible leadership development programmes specific to ECE available (highly recommend that these are government funded). These programmes would provide current or aspiring leaders theoretical and practical information needed to succeed in their role. Funding is also required to support aspiring leaders to attend these leadership development programmes.

3. Government needs to support and fund leadership research and development programmes within ECE, in a similar way it has been supporting the growth of leadership research and development programmes in the school sector. In doing so, it will enable more extensive research on leadership in ECE, consequently resulting to a clearer understanding of what leadership actually means within an ECE context. 
To Researchers:

1. Further research on leadership within ECE, specifically focused on 'practical' skills and conceptual understandings a Professional Leader can use to be an effective leader, must be done. While literature regarding the theoretical aspects of leadership is helpful, it is equally, if not more beneficial for current and aspiring leaders to learn about hands-on leadership strategies they can apply in everyday settings. 


\section{References}

Aitken, H. (2013). Perspectives on leadership in early childhood education. In A. Grey

\& B. Clark (Eds.), Transformative teaching practices in early childhood education. Nga hurihanga ako kohungahunga (pp.117-128). New Zealand: Pearson.

Aubrey, C. (2007). Leading and managing in the early years. London: Sage Publications.

Bloom, P. (2003). Leadership in action: How effective directors get things done. USA: New Horizons.

Bloom, P. J., \& Bella, J. (2005). Investment in leadership training - the payoff for early childhood education. Young Children, 60(1), 32-40.

Brewster, C. \& Railsback, J. (2003). Building trusting relationships for school improvement: Implications for principals and teachers. Oregon, USA: Northwest Regional Educational Laboratory.

Briggs, M., \& Briggs, I. (2009). Developing your leadership in the early years. London/New York: Continuum International Publishing Group.

Bronfenbrenner, U. (1994). Ecological models of human development. International encyclopedia of education 2(3), pp.1643 - 1647.

Brownlee, P. (2008). Dance with me in the heart: The adults' guide to great infant parent partnerships. Christchurch: New Zealand Playcentre Federation.

Bryk, A.S. \& Schneider, B. (2002). Trust in schools: A core resource for improvement. New York: Russell Sage Foundation. 
Bryk, A.S. \& Schneider, B. (2003). Trust in schools: A core resource for school reform. Educational Leadership (60)6, $40-45$.

Clarkin-Phillips, J. (2009). Distributed leadership: Utilising everyone's strengths. Early Childhood Folio, 13: 22-6.

Covey, S. (1989). The 7 habits of highly effective people: Powerful lessons in personal change. US: Free Press

Curtis, D. \& Carter, M. (2010). The visionary director. A handbook for dreaming, organizing, and improvising in your centre. $\left(2^{\text {nd }}\right.$ Ed). USA: Redleaf Press.

Denscombe, M. (2007). The good research guide for small-scale social research projects. ( $3^{\text {rd }}$ Ed.). UK: Open University Press.

Education Review Office (2011). Evaluation at Glance: What ERO knows about effective schools. Wellington: Author.

Evans, R. (2000). The authentic leader. In Jossey-Bass, The Jossey-Bass reader on educational leadership (pp. 287-308). San Francisco, CA: Author.

Fasoli, L., Scrivens, C., \& Woodrow, C. (2007). Challenges for leadership in Aotearoa/New Zealand and Australian early childhood contexts. In L. Keesing Styles \& H. Hedges (Eds.), Theorising early childhood practice: Emerging dialogues (pp. $231-253$ ).

Grey, A. (2004). The quality journey: Is there a leader at the helm? New Zealand Research in Early Childhood Education, 7, 91-102. 
Garvey-Berger, J. (2012). Changing on the job: Developing leaders for a complex world. Stanford, California: Stanford University Press.

Goleman, D. (1996). Emotional intelligence: why it can matter more than IQ. London: Bloomsbury.

Harris, A. (2003). Teacher leadership as distributed leadership: Heresy, fantasy or possibility? School Leadership and Management (23)3, 313 - 324.

Harris, A. (2009). Distributed leadership: Different perspectives. Netherlands: Springer.

Hipp, K. \& Huffman, J. (2010). Demystifying the concept of professional learning communities. In K.K. Hipp \& J.B. Huffman (Eds.), Demystifying professional learning communities: School leadership at its best. United Kingdom: Rowman \& Littlefield Education (pp. 11 - 21).

Johnson, R. \& Christensen, L. (2014). Educational research: Quantitative, qualitative and mixed approaches ( $5^{\text {th }}$ Ed.). USA: Sage Publications.

Jordan, B. (2008). Leadership leading learning and teaching: Leadership practices in early childhood resulting in learning for children. Journal of Educational Leadership, Policy and Practice, 23(2), $74-86$.

Jovanovic, S., \& Roder, J. (2008). New frames of reference: Asking questions as part of leadership activity. The First Years: Nga Tau Tuatahi. New Zealand Journal of Infant and Toddler Education, 10 (1), 8-12.

Kouzes, J.M. \& Posner, B.Z. (2007). The leadership challenge. $4^{\text {th }}$ Ed. San Francisco, CA: Jossey-Bass.

Kousez, J.M. \& Posner, B.Z. (2012). The leadership challenge ( $5^{\text {th }}$ Ed.) San Francisco, CA: Jossey Bass. 
Lambert, L. (1998). How to build leadership capacity. Educational Leadership (55)7, 17-19.

Lewicki, R. J., \& Bunker, B. B. 1996. Developing and maintaining trust in work relationships. In R. M. Kramer \& T. R. Tyler (Eds.), Trust in organizations: Frontiers of theory and research: 114-139. Thousand Oaks, CA: Sage Publications.

Ministry of Education. (1996). Te whāriki: He whāriki mātauranga mō ngā mokopuna o Aotearoa early childhood curriculum. Wellington: Learning Media.

Mutch, C. (2013). Doing educational research (2 $2^{\text {nd }}$ Ed.) New Zealand: NZCER Press.

Neuman, W. (2003). Social research methods: Qualitative and quantitative approaches. (5 $5^{\text {th }}$ Ed.) Boston: Allyn \& Bacon.

Notman, R. (2011). Building leadership success in a New Zealand Education Context. In R. Notman (Ed.), Successful educational leadership in new zealand: Case studies of schools and an early childhood centre. Wellington: NZCER Press.

Nupponen, H. (2006). Leadership concepts and theories: Reflections for practice for early childhood directors. Australian Journal of Early Childhood, 31(1), 43 - 50.

Ord, K., Mane, K., Smorti, S., Carroll-Lind, J., Robinson, L., Arstrong-Read, A., BrownCooper, P., Meredith, E., Rickard, D. \& Jalal, J. (2013). Te whakapakari kaiarahi ahuatanga ako kohungahunga. Developing pedagogical leadership in early childhood education. Wellington: Te Tari Puna Ora o Aotearoa/New Zealand Childcare Association.

Punch, K. (2009). Introduction to social research: Quantitative and qualitative approaches ( $2^{\text {nd }}$ Ed.) London: Sage Publications. 
Robertson, J. (2016). Coaching leadership: Building educational leadership capacity through partnership (2 $\left.{ }^{\text {nd }} E d\right)$. Wellington: NZCER.

Robinson, V.M., Hohepa, M. \& Llyod, C. (2009). School leadership and student outcomes identifying what works and why: Best evidence synthesis (BEST). Wellington: Ministry of Education.

Rodd, J. (2006). Leadership in Early Childhood (3 ${ }^{\text {rd }}$ Ed). Crows Nest, NSW: Allen \& Unwin.

Rodd, J. (2013). Leadership in Early Childhood. The pathway to professionalism. (4 ${ }^{\text {th }}$ Ed). England: Open University Press.

Rogers, C. (1961). On becoming a person. Boston: Houghton Mifflin.

Siraj-Blatchford, I. \& Hallet, E. (2014). Effective and caring leadership in the early years. USA: Sage.

Spillane, J. (2006). Distributed leadership. Sand Francisco: Jossey-Bass.

Stephenson, S. (2009). Leading with trust: How to build strong school teams. USA: Solution Tree Press.

Stoll, L. (2011). Leading professional learning communities. In J. Robertson \& H. Timperley (Eds)., Leadership learning (pp.103 - 117). USA: Sage

Thornton, K., Wansbrough, D., Clarkin-Phillips, J., Aitken, H., \& Tamati, A. (2009). Conceptualising leadership in early childhood education in Aoteroa New Zealand. Wellington, New Zealand: New Zealand Teachers Council.

Thornton, K. (2010). 'School leadership and student outcomes': The best evidence synthesis iteration: Relevance for early childhood education and implications for leadership practice. Journal of Educational Leadership, Policy and Practice (25)1, pp.31-41. 
Thornton, K. \& Cherrington, S. (2014). Leadership in professional learning communities. Australasian Journal of Early Childhood, 39(3), 94 - 103

Tschannen-Moran, M. \& Hoy, W. (1998). Trust in schools: a conceptual and empirical analysis. Journal of Educational Administration (36)6, 334 - 352.

Tuckman, B. W., \& Jensen, M. A. C. (1977). Stages of small-group development revisited. Group \& Organization Studies (Pre-1986), 2(4), 419. Retrieved from https://search-proquestcom.helicon.vuw.ac.nz/docview/232434254?accountid=14782

Yin, R. (2003). Case study research design and methods. ( ${ }^{\text {rd }}$ Ed). USA: Sage Publications. 
Appendices 


\section{Our relationship:}

1. How would you describe our professional relationship before I became the Head Teacher?

$\square$ Excellent $\square$ Good $\square$ Average $\square$ Fair $\square$ Poor

Please explain:

2. Since becoming the Head Teacher, has our professional relationship changed (if at all)?

$\square$ To a great extent $\square$ Somewhat $\square$ Very little $\square$ Not at all

3. In what ways has our professional relationship changed since I became the Head Teacher?

\section{Your trust in my Leadership:}

4. Read through the list of traits in the table below (more on the next page) and select five traits you believe is most important for a leader to have.

1.

2.

3.

4.

5.

\begin{tabular}{|l|l|l|l|}
\hline \multicolumn{4}{|c|}{ Some Traits We Associate with Good Leaders } \\
\hline Assertive & Calm & Collaborative & Compassionate \\
\hline Confident & Consistent & Courageous & Creative \\
\hline Decisive & Determined & Direct & Engaging \\
\hline Enthusiastic & Ethical & Helpful & Knowledgeable \\
\hline Objective & Empathetic & Fair & Flexible \\
\hline Friendly & Generous & Good Listener & Honest \\
\hline Humorous & Inquisitive & Inspiring & Intelligent \\
\hline
\end{tabular}




\begin{tabular}{|l|l|l|l|}
\hline Optimistic & Organized & Passionate & Patient \\
\hline Respectful & Trustworthy & Open & Problem Solver \\
\hline Responsible & Resourceful & Risk Taker & Visionary \\
\hline
\end{tabular}

7. Would you say I possess the traits you identified above as being important for a leader to have?

$\square$ All (5 traits) $\square$ Most (3 - 4 traits) $\square$ Some ( $1-2$ traits) $\square$ None

8. At this point in time, how much do you trust me as a Head Teacher?

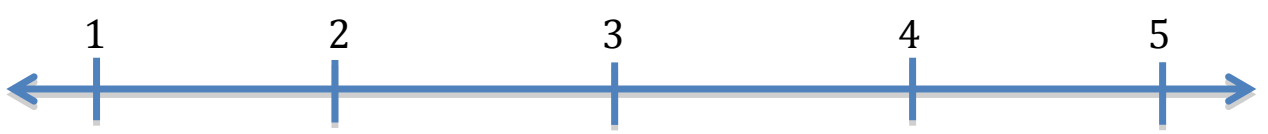

Not at all

To a great extent

9. In what ways have I gained your current level of trust as Head Teacher? (Tick as appropriate)

$\square$ I've got to know you quite well over time.

$\square$ You are reliable. You keep your word, i.e. you'll do what you say you'll do.

$\square$ You support me well with my professional goals.

$\square$ You keep me well informed and include me in decision making when necessary.

$\square$ You are open and honest, and provide constructive feedback when needed.

$\square$ You are always available for a chat.

$\square$ I feel respected and valued by you.

$\square$ You're a good listener.

$\square$ other (Please explain)

10. Suggestions on how I can gain your trust (further) as a Head Teacher?

11. Do you feel like you are growing professionally with me as the Head Teacher, i.e. do I motivate/challenge/inspire you? Please explain.

12. Is there anything within my leadership practice that I can/should improve/change? Please explain. 
Verbally inform and remind participants before interview starts -

"Thank you for agreeing to participate in this research. Before we go any further, I want to reiterate the focus of this study, and that is on $\underline{\mathbf{m y}}$ leadership practice. Through this research I wish to learn about conceptual understandings and leadership practices that will help strengthen the relational trust between a Professional Leader (me) and the team (you). [Define relational trust?] Data gathered from our conversation today, as well as the survey you've filled out, will be thematically analyzed to identify overarching themes or concepts within these data. I would like to reassure you that any information you share in this conversation would only be used for my research. This will not affect our professional relationship in any way. If there's a question you do not want to answer, please say so and I will respect that. If at any point in time during this interview you start getting uncomfortable, please say so and we will end this conversation. Should you have any concerns at all about this whole process (of me being a researcher as well as a Head Teacher), please let me know first. Otherwise, please let (contact person) know."

\section{Questions about Leadership:}

1. What is your definition of leadership (in early childhood education)?

a. (Possible Probing) Can you tell me more?

b. (Possible Probing) Can you explain that further?

2. What kind of responsibilities and/or "jobs" do you understand a person in a leadership position has?

a. (Possible Probing) Can you tell me more?

b. (Possible Probing) Can you explain that further?

c. (Possible Probing) Can you give me an example?

3. What kind of skills/character/traits do you believe is important for a person in a leadership position to have?
a. (Possible Probing) Can you tell me more?
b. (Possible Probing) Can you explain that further?
c. (Possible Probing) Can you give me an example?

\section{Questions about Relational Trust}

1. My research focus is on the relational trust between the Professional Leader and the team. How do you define/what is your understanding of (relational) trust?

a. (Possible Probing) Can you tell me more?

b. (Possible Probing) Can you explain that further? 
c. (Possible Probing) Can you give me an example?

2. Is having trust in the Professional Leader/being able to trust the Professional Leader important to you?

a. (Possible Probing) Why? Why not?

b. (Possible Probing) In what ways is it important?

c. (Possible Probing) Can you tell me more?

d. (Possible Probing) Can you explain that further?

e. (Possible Probing) Can you give me an example?

3. How can a Professional Leader gain (or not gain) your trust?

f. (Possible Probing) Can you tell me more?

g. (Possible Probing) Can you explain that further?

h. (Possible Probing) Can you give me an example?

\section{Specific Questions about my leadership practice:}

1. Those skills/character/traits you believe is important for a person in leadership position to have, do you see these in me?

i. (Possible Probing) Why? Why not?

j. (Possible Probing) Can you tell me more?

k. (Possible Probing) Can you explain that further?

l. (Possible Probing) Can you give me an example?

2. What are your expectations of me as a leader, for example, the kind of support you'd like/need from me?

a. (Possible Probing) Am I meeting/Have I met those expectations?

b. (Possible Probing) Can you tell me more?

c. (Possible Probing) Can you explain that further?

d. (Possible Probing) Can you give me an example? 
Survey 2

Appendix C

Part 1:

Our relationship:

5. In the last 6 months, has our professional relationship changed (if at all)?

$\square$ To a great extent $\square$ Somewhat $\square$ Very little $\square$ Not at all

6. How has it changed (if at all)? Please explain

\section{Your trust in my Leadership:}

7. Please identify at least three traits you believe a Professional Leader should have.

1.

2.

3.

4.

5.

13. Do you see these traits in me? Yes or No?

14. How much do you trust me as a Professional Leader at this point in time?

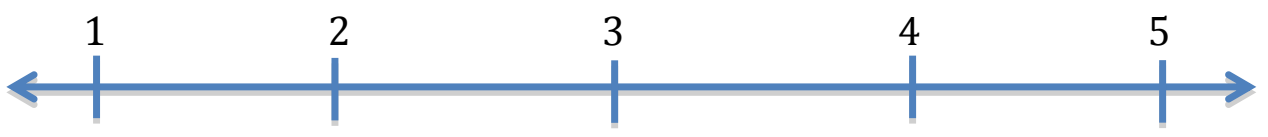

Not at all

To a great extent

15. Has your trust in me as a Professional Leader grown or lessened in the last 6 months?

16. Please explain why and how it has grown or lessened. 
17. In what ways can I gain your trust further?

18. What else can I do to further grow and become a better Professional Leader?

19. Do you feel like you have grown professionally in the last six months with me as the Professional Leader? Please explain.

\section{Part 2:}

These next set of questions are particularly about my leadership skills and competencies.

Please answer 'yes' or 'no' and further explain where you can.

Communication: The ability to give and gather information and to actively manage the communication process.

1. I (Professional Leader) asks questions to find out your real views and to check whether I understood you right.

$\square$ Yes $\square$ No

Please explain:

2. My manner of communication, style and presence gives you a positive impression.

$\square$ Yes $\square$ No

Please explain:

3. I listen to and consider your views and perspetives.

$\square$ Yes $\square$ No

Please explain:

4. I state my own views/ideas clearly and concisely.

$\square$ Yes $\square$ No

Please explain: 
5. I handle disagreement constructively.

$\square$ Yes $\square$ No

Please explain:

Developing Others: The ability to improve performance through training and development of individuals and teams.

1. I create and inspire a positive learning environment.

$\square$ Yes $\square$ No

Please explain:

2. I encourage you to (continuously) challenge yourself professionally.

$\square$ Yes $\square$ No

Please explain:

3. I coach and mentor you according to your strengths as well as your aspirations.

$\square$ Yes $\square$ No

Please explain:

Integrity and Ethical Management: The ability to work ethically according to the New Zealand Education Council's Code of Ethics.

1. I take and accept responsibility for my own work and decisions.

$\square$ Yes $\square$ No

Please explain:

2. I admit when I've made (a) mistake/s.

$\square$ Yes $\square$ No

Please explain:

3. I stick to decisions which have been made (by me, or by the team) and stay true to my word.

$\square$ Yes $\square$ No

Please explain:

4. I am fair and use my positional power with care and restraint.

$\square$ Yes $\square$ No 
Please explain:

Motivation: The ability to support and encourage individuals and teams, so that they give their best.

1. I believe in your abilities.

\section{$\square$ Yes $\square$ No}

Please explain:

2. I give you praise and open (public) recognition.

$\square$ Yes $\square$ No

Please explain:

3. I have the knowledge, experience and maturity to support you (individually) and the team (as a whole) through difficult circumstances (i.e. staff changes).

$\square$ Yes $\square$ No

Please explain:

4. I motivate and inspire you through personal example (role modeling).

$\square$ Yes $\square$ No

Please explain:

Relationship Building: The ability to get on well with a wide range of people and build long term trusting relationships.

1. I bring tensions (i.e. between teachers) to surface, help to resolve conflicts (for example by encouraging courageous conversations) and produce positive outcomes.

$\square$ Yes $\square$ No

Please explain:

2. I build/have rapport with people (team, children, families).

$\square$ Yes $\square$ No

Please explain:

3. I got out of my way to develop trust in relationships.

$\square$ Yes $\square$ No

Please explain: 
4. I notice when you need help and support.

$\square$ Yes $\square$ No

Please explain:

Team Working: The ability to contribute to teams and to improve their effectiveness through personal commitment.

1. I develop ideas and solutions jointly with you and/or the team.

$\square$ Yes $\square$ No

Please explain:

2. I encourage a strong sense of team spirit.

$\square$ Yes $\square$ No

Please explain:

3. I focus the team on what will contribute to success (vision) in the long term.

$\square$ Yes $\square$ No

Please explain: 


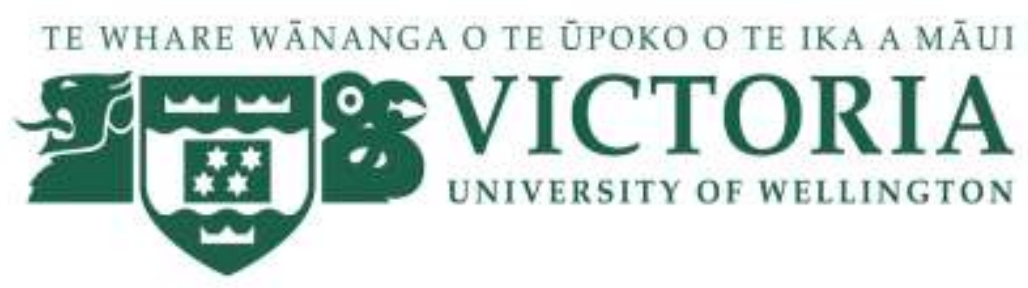

Appendix D

Information Sheet for Participants

\section{Research Project: Strengthening the Relational Trust between a Professional Leader and the Team}

Tena Koe

Dear

As part of my completion towards a Master of Education, I will be undertaking research around leadership in early childhood education at (Centre) The aim of my thesis is to investigate leadership practices and conceptual understandings that will help strengthen the relational trust (Bryk \& Schneider, 2003) between myself, as the Professional Leader, and the team.

This research will take the form of a case study, where the sole focus will be on $\underline{m y}$ leadership. Should you agree to partake, your participation will consist of:

- Completion of 2 anonymous online surveys (approximately $5-10$ minutes long). One survey will be given out at the beginning of the research, and another one approximately 6 months later.

- 2 informal conversational interviews (approximately 30 minutes -1 hour)

The online survey will take approximately $5-10$ minutes to complete and a link will be emailed out to you upon receiving your consent form. One survey will be given out at the beginning of the research as part of the initial data collection period. Another one will be given out approximately 6 months later to track the difference between your answers at the start of the study and your answers at the end of the study. This online survey will be anonymous and in no way can identify your responses.

Informal conversational interviews will take approximately 30 minutes to an hour. In this interview I will ask you a few questions specifically about my leadership practices. I will audio record these interviews, and have it transcribed by a professional transcriber (who will sign a confidentiality agreement prior to commencing). These interviews will take place at a date and time that will suit us both. A transcript of the interview will be sent to you as soon as possible after the interview for your verification and/or amendment. Another interview will be held approximately 3 months later to track the difference between your answers at the start of the study and your answers at the end of the study. 
Any information shared during these interviews will be strictly used for this research, and will not influence nor affect our professional relationship in any way. During the interview, you may ask to not answer any questions, and/or ask to stop the interview should you choose to. Should this occur, I ask for your permission to utilize this instance as part of my data collection.

Thorough ethical considerations have been taken, however, due to the ethically challenging nature of this research being conducted at my place of work, as well as myself being the Head Teacher of the centre and in a position of power, should you have any questions or concerns about my work, i.e. role conflict between my role as a Professional Leader at (Centre), and as a researcher, as a result of undertaking this research, please feel free to speak with (Centre) co-owner, (Contact Person) either in person or via email (Contact Person's Email).

Should such an instance occur (i.e. a concern was shared with [Contact Person]) you have the option of allowing (Contact Person) to either share these concerns with me or not. With your permission, should you allow (Contact Person) to share what your concerns were with me, I would like to use this instance as part of my data collection. Anonymity and confidentiality will be maintained by (Contact Person) when your concerns are shared with me to honour your privacy and safety.

Your participation is voluntary and you are under no obligation to agree to be a part of it. A pseudonym will be used for yourself. The information you provide will be reported and published in such a way that it will not identify you as its source. Interview transcripts, and other documentary evidence gathered for this study will be kept in a password-protected file in a locked filing cabinet at a secure location. You will be offered a copy of the thesis once it is completed.

If you have any questions about participating in this research, please feel free to speak with me either in person, or via email ofrasibrig@myvuw.ac.nz for further information. For further questions or specific queries about this research, you are welcome to contact my thesis supervisor, Dr. Kate Thornton via email kate.thornton@vuw.ac.nz.

If you agree to participate, please print off the consent form, fill it in and hand it to me by Friday, $13^{\text {th }}$ November 2015.

Should you feel the need to withdraw from this research, you may do so without question before the end of the data collection period, which is the $30^{\text {th }}$ of April 2016. Responses collected will form the basis of my research and will be put into a written report on an anonymous basis. All material collected will be kept confidential. No other person, besides me and my supervisor, Dr. Kate Thornton, will see the surveys or transcripts of discussions. The thesis will be submitted for the marking to the School of Educational Policy and deposited in the University Library. It is intended that one or more articles will be submitted for publication in scholarly journals. Surveys and transcripts will be destroyed five years after the end of this research. 
This research has been approved by Victoria University Human Ethics Committee. If you have any concerns about the ethical conduct of the research you may contact the Victoria University HEC Convener: - Associate Professor Susan Corbett. Email susan.corbett@vuw.ac.nz or telephone+64-4-463 5480.

Thank you in anticipation for your time and help in making this research possible.

Yours sincerely,

Brigitte Alamani 


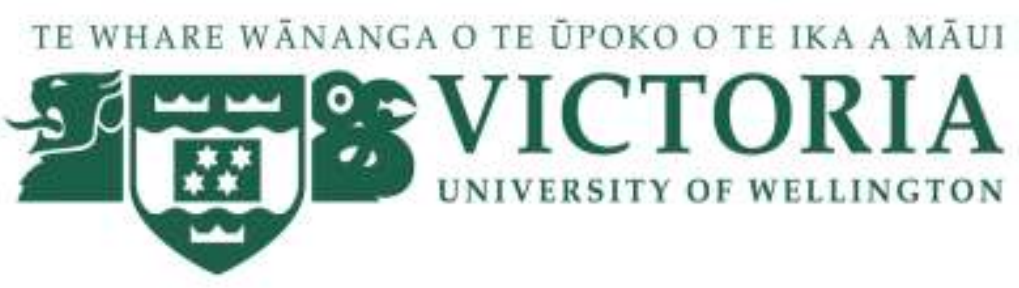

Consent Form for Participants

\section{Research Project: Strengthening the Relational Trust between a Professional Leader and the Team}

I have been given and have understood an explanation relating to the nature and purpose of this research project. I have had the opportunity to ask questions about it.

I am willing to complete an online survey and participate in an interview. Should I choose not to answer any questions during the interview, or ask to stop the interview, I understand I have the option of allowing the researcher to use this occurrence as part of the data collection.

I understand that should I have any concern/s about the researcher's work, I have the option of speaking with (Contact Person) about it. I understand that, should I choose, I may give (Contact Person) permission to share my concern/s with the researcher who may use this occurrence as part of the data collection. I also understand that my anonymity will be maintained from the researcher in this instance.

I understand that the data collected will be kept secure. Only the researcher and a supervisor will have access to the data. I also understand that all the data collected will be destroyed 5 years after the conclusion of the study.

I understand that my name will not be revealed in any publication arising from this research; instead pseudonyms will be used.

I understand that the research may be presented in academic or professional journals.

I understand that I can withdraw from this study without giving a reason up until the conclusion of the data collection.

Name:

Signature: Date: 


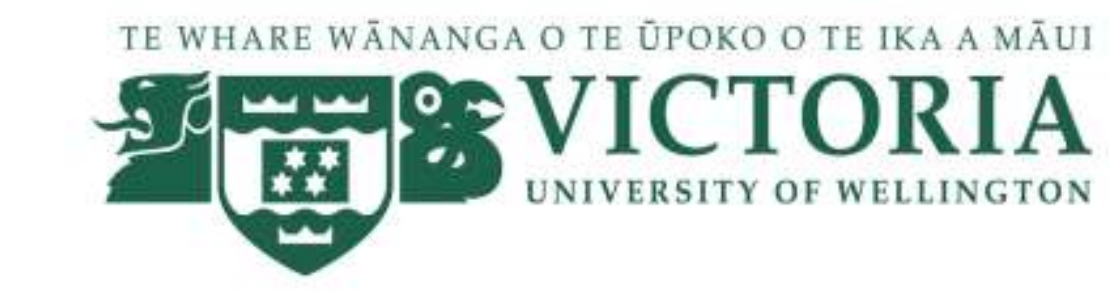

Information Sheet for Participant (Observer \& 'Contact Person')

Appendix E

\author{
Research Project: Strengthening the Relational Trust between a Professional Leader \\ and the Team
}

Tena Koe

Dear

As part of my completion towards a Master of Education degree, I am undertaking research around leadership in early childhood education at (Centre). The aim of my thesis is to investigate leadership practices and conceptual understandings that will help strengthen the relational trust (Bryk \& Schneider, 2003) between myself, as the Professional Leader, and the team.

This research will take the form of a case study, where the sole focus will be on my leadership. Should you agree to partake, your participation will consist of:

- 4 written observation of my leadership practice, approximately $1-2$ hours at a time (One in the morning, one in the afternoon, and two at a team meeting evening).

- Being the participants/teachers' contact ("go-to") person should they have any concerns about my (research) work

I ask that you observe me lead at least two (consecutive or not) team meetings, as well as on both ends of the day (one in the morning, and one in the afternoon). The focus of these observations will be on the way I communicate, both verbal and nonverbal (including body language and facial expressions), along with the way I relate with the team. Through these observations, I hope to discover any habits/practices I may or may not be aware of, that could either support or hinder my goal of strengthening the relational trust between the team and myself.

As I aim to begin my data analysis by 2 May 2016, please can I have these written observations by 29 April 2016.

Thorough ethical considerations have been taken, however, due to the ethically challenging nature of this research being conducted at my place of work, as well as myself being the Head Teacher of the centre and in a position of power, I ask that you be the participants/teachers' contact person should they have any concerns about my work, i.e. role conflict between my role as the Head Teacher and as a researcher, and are not comfortable discussing these concerns with me directly. 
Should a participant/teacher come to you with a concern about my work, with their permission, I ask that you share this concern with me, whilst maintaining confidentiality and the teacher's anonymity to honour his/her privacy and safety. I may use these concerns as part of my data collection.

Your participation is voluntary and you are under no obligation to agree to be a part of it. A pseudonym will be used for yourself. The information you provide will be reported and published in such a way that it will not identify you as its source. Interview transcripts, and other documentary evidence gathered for this study will be kept in password-protected file in a locked filing cabinet at a secure location. You will be offered a copy of the thesis once it is completed.

If you have any questions about participating in this research, please feel free to speak with me either in person, or via email ofrasibrig@myvuw.ac.nz for further information. Should you have any questions or concerns about my work, i.e. role conflict between my role as a Professional Leader at (Centre), and as a researcher, as a result of undertaking this research, feel free to speak with me, or with my thesis supervisor, Dr. Kate Thornton via email kate.thornton@vuw.ac.nz.

If you agree to participate, please print off the consent form, fill it in and hand it to me by 28 October 2015.

Should you feel the need to withdraw from this research, you may do so without question at any time before the end of the data collection period, which is the $30^{\text {th }}$ of April 2016. Responses collected will form the basis of my research and will be put into a written report on an anonymous basis. All material collected will be kept confidential. No other person, besides my supervisor, Dr. Kate Thornton, and me will see the surveys or transcripts of discussions. The thesis will be submitted for the marking to the School of Educational Policy and deposited in the University Library. It is intended that one or more articles will be submitted for publication in scholarly journals. Surveys and transcripts will be destroyed five years after the end of this research.

This research has been approved by Victoria University Human Ethics Committee. If you have any concerns about the ethical conduct of the research you may contact the Victoria University HEC Convener: - Associate Professor Susan Corbett. Email susan.corbett@vuw.ac.nz or telephone+64-4-463 5480.

Thank you in anticipation for your time and help in making this research possible.

Yours sincerely,

Brigitte Alamani 


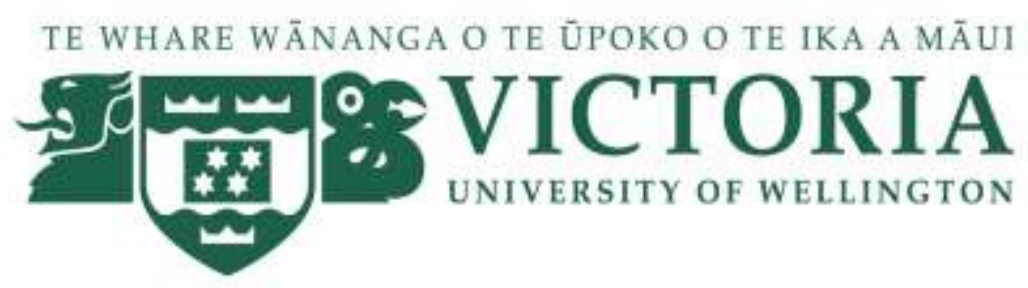

\section{Consent Form for Observer and Contact Person}

\section{Research Project: Strengthening the Relational Trust between a Professional Leader and the Team}

I have been given and have understood an explanation relating to the nature and purpose of this research project. I have had the opportunity to ask questions about it.

I agree to observe the researcher's leadership practices in 4 instances and provide written documentation of these observations as part of her data collection.

I agree to be a Contact Person for the participants should they have any concerns about the researcher's work and not feel comfortable approaching the researcher directly. I will, with the participant's permission, share these concerns with the researcher, whilst maintaining the participant's anonymity. I understand that these concerns/this instance, with the participant's permission, may also be used as part of the data collection.

I understand that the data collected will be kept secure. Only the researcher and a supervisor will have access to the data. I also understand that all the data collected will be destroyed 5 years after the conclusion of the study.

I understand that my name will not be revealed in any publication arising from this research; instead pseudonyms will be used.

I understand that the research may be presented in academic or professional journals.

I understand that I can withdraw from this study without giving reason up until the conclusion of the data collection.

Name:

Signature: Date: 


\begin{tabular}{|c|c|c|c|c|c|}
\hline & P1 & P2 & P3 & P4 & P5 \\
\hline $\begin{array}{l}\text { Q1. } \\
\text { Definition of } \\
\text { Leadership } \\
\text { in ECE }\end{array}$ & $\begin{array}{l}\text {-Child focused } \\
\text {-Understands } \\
\text { importance of } \\
\text { team harmony } \\
\text {-Can put } \\
\text { personal } \\
\text { feelings and } \\
\text { stuff away } \\
\text { when they're } \\
\text { in the Head } \\
\text { Teacher (HT) } \\
\text { role } \\
\text {-Someone who } \\
\text { doesn't judge, } \\
\text { doesn't } \\
\text { criticize or } \\
\text { make } \\
\text { assumptions }\end{array}$ & $\begin{array}{l}\text {-Being a role } \\
\text { model } \\
\text {-Distributed } \\
\text { Leadership: } \\
\text { There's a } \\
\text { leader, then } \\
\text { that leader } \\
\text { delegates, or } \\
\text { asks for } \\
\text { people to } \\
\text { assist with } \\
\text { various } \\
\text { things } \\
\text {-Being the } \\
\text { overall } \\
\text { responsible } \\
\text { person, but } \\
\text { having other } \\
\text { people } \\
\text { supporting } \\
\text { and helping }\end{array}$ & $\begin{array}{l}\text {-Inspirational } \\
\text {-Professional } \\
\text {-Knows what } \\
\text { they're talking } \\
\text { about } \\
\text {-Can be a good } \\
\text { mentor } \\
\text {-Knows } \\
\text { regulations } \\
\text {-Answers } \\
\text { questions } \\
\text {-Offers lots of } \\
\text { support and } \\
\text { encouragement } \\
\text {-Trust the team }\end{array}$ & $\begin{array}{l}\text {-Focus on } \\
\text { Education or } \\
\text { a vision on } \\
\text { education } \\
\text { and learning } \\
\text {-Leading } \\
\text { teachers to be } \\
\text { able to fully } \\
\text { support } \\
\text { children in } \\
\text { their learning } \\
\text { needs } \\
\text {-Helping } \\
\text { teachers to be } \\
\text { their biggest } \\
\text { selves } \\
\text {-To support } \\
\text { them with } \\
\text { their } \\
\text { knowledge } \\
\text { and their } \\
\text { skills } \\
\text {-Identifying } \\
\text { their } \\
\text { strengths } \\
\text {-(Give) } \\
\text { affirmation } \\
\text {-Seeing } \\
\text { possible } \\
\text { weaknesses } \\
\text { and tactfully } \\
\text { seeing where } \\
\text { they're at } \\
\text {-Supporting } \\
\text { and helping } \\
\text { them } \\
\text { overcome or } \\
\text { grow in } \\
\text { particular } \\
\text { areas that } \\
\text { you might } \\
\text { identify they } \\
\text { might need } \\
\text { more growth } \\
\text { in } \\
\text { together }\end{array}$ & $\begin{array}{l}\text {-Friendship } \\
\text {-Mentoring } \\
\text {-Guidance } \\
\text {-Accountability } \\
\text {-Needs to } \\
\text { understand the } \\
\text { sector } \\
\text {-Needs to be } \\
\text { open with their } \\
\text { knowledge and } \\
\text { understanding } \\
\text {-Guiding others } \\
\text {-Ensuring goals } \\
\text { and philosophy } \\
\text { are put into } \\
\text { place }\end{array}$ \\
\hline
\end{tabular}

